\title{
Injectable Vaginal Hydrogels as a Multi-Drug Carrier for Contraception
}

\author{
Lei Nie ${ }^{1,2, *,+} \mathbb{C}$, Peng Zou ${ }^{3,+}$, Jing Dong ${ }^{2}$, Meng Sun ${ }^{1,2}$, Peng Ding ${ }^{1,2}$, Yanting Han ${ }^{1,2}$, \\ Chingching $\mathrm{Ji}^{4}$, Qiuju Zhou ${ }^{5}$, Hongyu Yuan ${ }^{1,2}$ and Jinping Suo ${ }^{6}$ \\ 1 College of Life Sciences, Xinyang Normal University, Xinyang 464000, China; \\ sunmeng2010abc@163.com (M.S.); dingzhiyu120@163.com (P.D.); hanyt@xynu.edu.cn (Y.H.); \\ yhongyu92@163.com (H.Y.) \\ 2 Henan Key Laboratory of Tea Plant Biology, Xinyang Normal University, Xinyang 464000, China; \\ dongjing2018@126.com \\ 3 Downhole Technology Service Company, Bohai Drilling Engineering Company Limited, CNPC, Dagang, \\ Tianjin 300283, China; zoupeng621@163.com \\ 4 Institut für Chemie und Biochemie-Physikalische und Theoretische Chemie, Freie Universität Berlin, Takustr. \\ 3, 14195 Berlin, Germany; chi.ji91@gmail.com \\ 5 Analysis \& Testing Center, Xinyang Normal University, Xinyang 464000, China; zhouqiuju@iccas.ac.cn \\ 6 State Key Laboratory of Mould Technology, Department of Materials Science and Engineering, Huazhong \\ University of Science and Technology, Wuhan 430074, China; jinpingsuo@hust.edu.cn \\ * Correspondence: nieleifu@yahoo.com or nielei@xynu.edu.cn; Tel.: +86-136-0062-1068 \\ + These authors contributed equally to this work and should be considered co-first authors.
}

Received: 1 March 2019; Accepted: 15 April 2019; Published: 19 April 2019

check for updates

\begin{abstract}
Injectable intravaginal hydrogels could deliver drugs systemically without hepatic first pass effect. This paper focuses on the contraceptive function of an injectable temperature-sensitive four-arm star-shaped poly( $D$,L-lactic-co-glycolic acid)-b-methoxy poly(ethylene glycol) (4sPLGA-mPEG) block copolymer hydrogels as a carrier of three drugs. In vitro controlled release profiles were investigated via HPLC, and it showed that the cumulative release amounts of indomethacin (IMC), gestodene (GSD), and ethinyl estradiol (EE) from copolymer hydrogels could be regulated by adjusting the lactide/glycolide (LA/GA) mol ratio. In addition, in vitro release profiles of IMC, GSD, and EE well corresponded to Higuchi model. The acute toxicity of copolymer hydrogels loaded with different dosage contents multi-drug was evaluated in vivo. As to the high dosage group, the uterus was hydropic at day 1 and ulcerated at day 5, followed with intestinal adhesion. Regarding the middle dosage group, no festering of tissues was observed and, blood coagulum existed in the uterus at different days. For low dosage group, no significant tissue necrosis was found. Finally, the antifertility experiments confirmed that hydrogels loaded with the multi-drug had an excellent contraceptive effect. The above results indicated that injectable copolymer hydrogel as a multi-drug carrier was promising as a novel contraception method.
\end{abstract}

Keywords: vaginal hydrogels; injectable; contraception; multi-drug release; mucoadhesive; biodegradability

\section{Introduction}

In developing countries, the number of maternal deaths has been reduced by increasing the use of contraceptives over the past 30 years, simply by reducing the number of unintended pregnancies [1,2]. Surgical sterilization is the most prevalent method of contraception in the world, mainly including female sterilization (tubal sterilization) and male sterilization (vasectomy). However, surgical sterilization has the risk of death and serious morbidity, furthermore, the risk of ectopic pregnancy still [3]. Nowadays, intrauterine devices (IUDs) are one of the most widely used modern 
reversible contraception methods. Previous studies have shown that IUDs could cut down the risk of pelvic inflammatory disease and sexually transmitted infections for women but the risk of cervical chlamydial or gonococcal infections increased dramatically [4-7]. Combined estrogen-progestogen oral contraceptive pills (OCPs) are the other most widely used modern contraceptive method. However, a pooled analysis indicated that OCPs users have an increased risk of cervical cancer and such risk raised with prolongation of using time [8,9]. Evidence for the safety of woman fitted with IUDs or OCPs with HIV/AIDS was scarce, but existing studies showed that IUDs and/or OCPs still caused some adverse health effects, including disease progression in infected women and HIV transmission to uninfected partners [10].

It is well known that the vaginal route is convenient and effective for contraception [11]. The vaginal route has many advantages due to its large surface area, rich blood supply, relatively high permeability of many drugs, and self-insertion. Apart from this, avoidance of the gastrointestinal absorption and the hepatic first-pass metabolism, the presence of uniform dense vascularization and the high mucosal permeability have made vaginal route widely used for many drugs administrations [12,13]. For example, the contraceptive vaginal ring (CVR) can eliminate the need for daily dosing and improve the contraceptive effects [14]. Saxena et al. designed vaginal ring which was composed of a hydrogel of 2-hydroxyethyl methacrylate (HEMA) and sodium methacrylate (SMA), and the nonhormonal contraceptives and 3'-Azido-3'-deoxythymidine (AZT) as an anti-HIV agent could be delivered by such vaginal ring [15]. A large variety of vaginal forms have been developed and commercialized in recent years including tablets, hydrogels, creams, rings, foams, films, etc [12]. The traditional vaginal forms, such as creams, rings, vaginal suppositories, and tablets, have been associated with some limitations of leakage, messiness, and relatively short residence time mainly due to the self-cleaning action of the vaginal tract $[16,17]$.

The ideal vaginal drug route should be easy to use (self-administrated, surgical procedure free), discreet, reversible, painless to the patient (minimal interference with body function and daily life), cost-effective, widely available (high bioavailability with other medications), and safe for continuous administration [18]. The vaginal condition changes due to numerous physiological and non-physiological factors, such as the menstrual cycle of women or menopause, and also after sexual intercourses. The natural clearance process of vaginal secretions, commonly referred to as mucus, which is another important parameter interfere with the performance of vaginal delivery system [19]. In the vagina, the mucus holds important physiological functions such as lubrication, and the mucus barrier protects the vagina against pathogens. The drugs through vaginal route need to across the mucus layer, then vaginal epithelial cells, and then, were absorbed by the body. Therefore, mucus plays an important role and significantly impact drug absorption or action [20].

Hydrogels with a three-dimensional polymeric matrix are semi-solid, made of small quantities of gelling excipient in relatively large amounts of liquids, but possessing more solid-like character [21]. Hydrogels are versatile and have been used to deliver microbicides, labor inducers, and other substances in the vagina [22]. Furthermore, the localized vaginal hydrogels delivery (mainly mucosal route) allows women to self-administer contraceptives, but it also reduces adverse effects and frequency of the dosage $[15,23]$. With excellent biocompatibility advantages, natural polymer hydrogels have been used as a vaginal drug delivery system [24]. Tania Furst et al. first obtained a sponge by lyophilization of cellulosic derivative hydrogels, and then the prepared sponge could be adhered to the vaginal cavity and rehydrated by the small amount of vaginal fluids to form hydrogels again as drug delivery system [12]. Jalalvandi et al. designed an in situ-forming and $\mathrm{pH}$-responsive hydrogel based on chitosan as mucoadhesive hydrogel for vaginal delivery of therapeutic agents [25]. Gelatin hydrogels using polysaccharides (e.g., maltodextrin, dextran, and sodium carboxymethyl cellulose) have been used in vaginal delivery of antimicrobials, such as metronidazole, for the treatment of bacterial vaginosis [26].

One problem through conventional hydrogels as vaginal drug delivery system is rapid removal from the application site, but also uneasy self-administration for users. Stimulus-responsive synthetic 
degradable hydrogels, such as in situ-forming hydrogels, is a good solution to overcome rapid removal, and their physical characteristics were altered as a result of exposure to changes of vaginal environments $[27,28]$. Thermosensitive vaginal hydrogels are capable of gelling in response to temperature change, such as, from ambient to body temperature [29]. Furthermore, thermosensitive hydrogels have great promise due to their stability, adhesion properties and adjustable drug release kinetics [30]. In general, gelation temperatures in the range of $25-37^{\circ} \mathrm{C}$ have been considered suitable for vaginal site application. Commonly synthetic polymers for thermosensitive hydrogels include $\mathrm{N}$-isopropyl acrylamide copolymers, poloxamers and their copolymers, poly(ethylene oxide)/poly ( $D, L$-lactic acid-co-glycolic acid) copolymers, and so on [31]. The terpolymer of $\mathrm{N}$-isopropyl acrylamide, butyl methacrylate, and acrylic acid was used as a thermosensitive and $\mathrm{pH}$-sensitive polymer hydrogel for loading and releasing microbicides for the prevention of sexual transmission of HIV and other sexually transmitted diseases (STDs) [32]. Poloxamer (such as F127 and F68) could be designed as the thermosensitive contraceptive vaginal hydrogel for in situ loading curcumin for contraception [33-35]. Wei et al. designed the poloxamer-based in situ vaginal hydrogels with loading nonoxynol-9 as a model drug, different poloxamer 407/poloxamer 188 ratios were used for adjusting hydrophilic content of hydrogel formulations, and further regulating hydrogels erosion, drug release, and intravaginal elimination [36]. The poloxamer with the clotrimazole loaded nanostructured lipid carriers could be diluted with simulated vaginal fluid (SVF) to form thermo-hydrogels for treating fungal vaginal infections [37].

Poly(ethylene glycol) (PEG)/Polyester copolymer hydrogels perhaps represented the most extensive research system in recent years, while the biodegradable rate was regulated by adjusting the ratio of lactic acid to glycolic acid (LA/GA). Ding et al. synthesized a thermo-gelling poly(lactic acid-co-glycolic acid)-poly(ethylene glycol)-poly(lactic acid-co-glycolic acid) (PLGA-PEG-PLGA) triblock copolymer, then the triblock copolymer could form to micelles in water and serve as a reservoir for the solubilization of hydrophobic levonorgestrel (LNG) molecules. The PLGA-PEG-PLGA thermo-gel markedly extended the release of LNG, which was promising for long-term contraception and fertility control [38]. The poly(lactide-co-glycolide) and polylactic acid polymer and a solvent mixture containing N-methyl-2-pyrrolidone and benzyl benzoate or triethyl citrate was be used as LNG-containing injectable in situ forming depot (ISD) system, then a long-time release of LNG was accomplished [39]. The star-shaped poly( $D, L$-lactic-co-glycolic acid)-b-methoxy poly(ethylene glycol) (4sPLGA-mPEG) block copolymer showed tuning sol-gel transition, controllable biodegradability, and excellent biocompatibility in vitro and in vivo, and also showed potential in many biomedical applications in our previous reports [40-42]. Here, the four-arm star-shaped 4sPLGA-mPEG block copolymer was used as vaginal hydrogel for delivering multi-contraceptive. Compared to a single drug, multi-drug showed much more promising application for contraception. A combination of releasing etonogestrel and ethinyl estradiol (EE) has been approved in the United States and in many countries throughout the world, and a Phase 3 clinical trial of a combined hormonal ring containing nestorone and EE has been completed. These findings suggested that bleeding patterns with the ethinyl estradiol/gestodene (EE/GSD) patch similar to EE/LNG (levonorgestrel LNG)-containing COC (combined oral contraceptive) [43].

In this work, the four-arm star-shaped 4sPLGA-mPEG block copolymer with different LA/GA mol ratios was synthesized by our previous reports with minor modifications. The prepared copolymer was dissolved in simulated vaginal fluid (SVF), the sol-gel transition behavior of the copolymer solution was examined. Then, three hormonal contraceptives, indomethacin (IMC), gestodene (GSD), and ethinyl estradiol (EE) were loaded into copolymer hydrogels during the sol-gel transition process, as shown in Scheme 1. The release profiles of three contraceptives in vitro were investigated via HPLC. At the same time, the synchronic release profiles of these three drugs were fitted by zero-order, first-order and Higuchi models. Finally, the acute toxicity and anti-fertility of multi-drug loaded hydrogels were investigated by injecting hydrogels into the vagina of female Sprague-Dawley (SD) rats. 


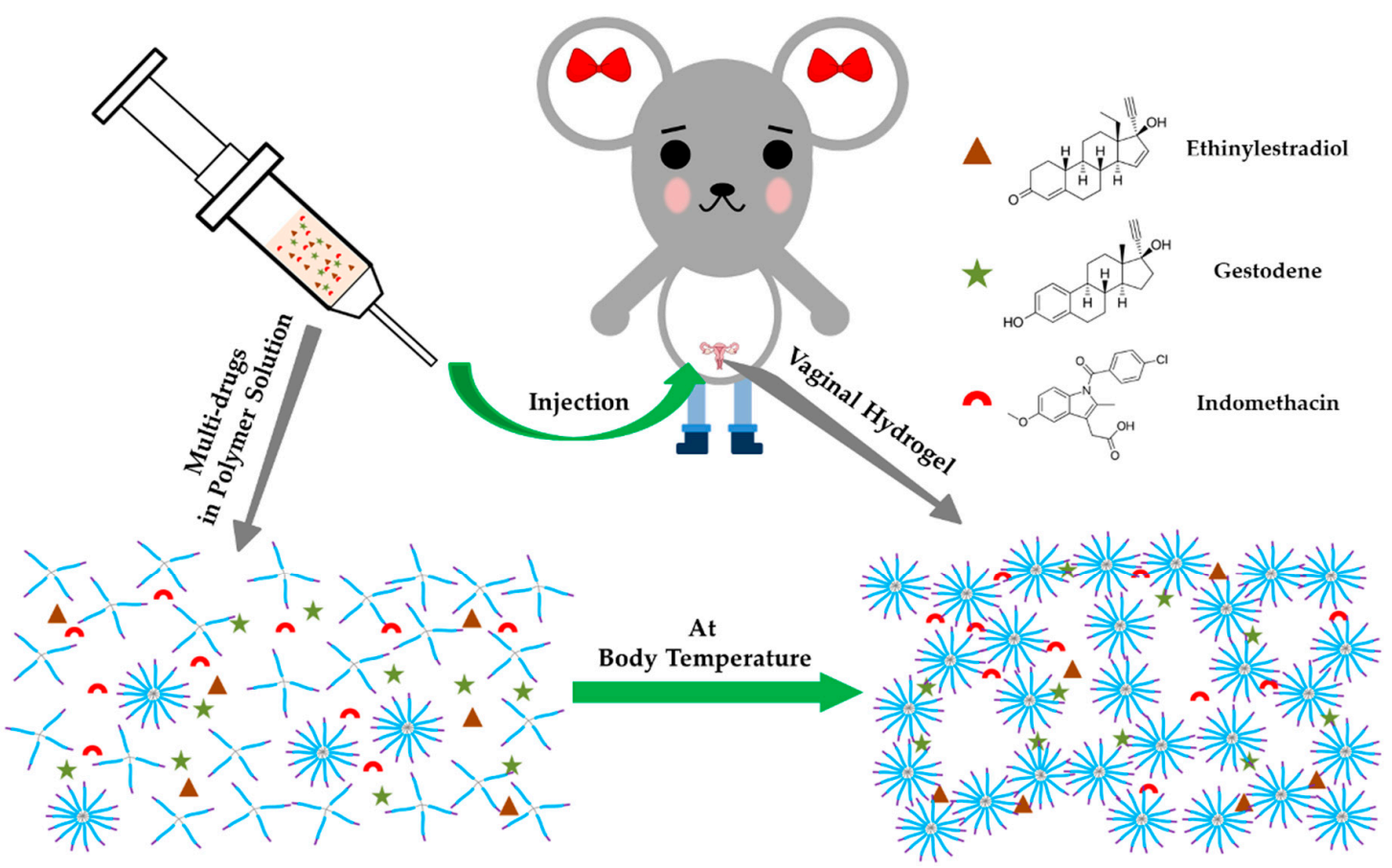

Scheme 1. Schematic illustration of multi-drug (Ethinylestradiol, Gestodene, and Indomethacin) loaded four-arm star-shaped poly( $D$,L-lactic-co-glycolic acid)- $b$-methoxy poly(ethylene glycol) (4sPLGA-mPEG) block copolymer hydrogels as vaginal hydrogels for contraception. Drugs were involved in block copolymer solution, then the solution was injected into the Sprague-Dawley (SD) rat vagina, multi-drug loaded hydrogels was formed with the help of body temperature.

\section{Materials and Methods}

\subsection{Materials}

DL-lactide (LA), glycolide (GA), monomethoxy poly(ethylene glycol) (mPEG, $M_{n}=550$ ), pentaerythritol (PTOL), succinic anhydride (SA), 4-(dimethylamino) pyridine (DMAP), 1,3-dicyclohexylacarbodiimide (DCC), and stannous octoate ( $\left.\mathrm{Sn}(\mathrm{Oct})_{2}\right)$ were purchased from Sigma Co., Ltd. Indomethacin (IMC) (99\% purity) was purchased from Aladdin Chemistry Co. Ltd. Gestodene (GSD) and ethinyl estradiol (EE) (microcrystalline powder, 99\% purity) were obtained from Beijing Zizhu Pharmaceutical Co., Ltd. HPLC-grade methanol was purchased from China National Medicines Co. Ltd. Ultrapure water was prepared by a Milli-Q50 SP Reagent Water System (Millipore Corporation, MA, USA) for the preparation of samples. Other reagents were of analytical grade.

\subsection{Preparation of Four-Arm Star-shaped poly(D,L-lactic-co-glycolic acid)-b-methoxy poly(ethylene glycol) (4sPLGA-mPEG) Block Copolymers}

The four-arm star-shaped poly( $D, L$-lactic-co-glycolic acid)-b-methoxy poly(ethylene glycol) (4sPLGA-mPEG) block copolymer was synthesized by our previous reports with minor modifications, as shown in Figure 1a [44]. The 4sPLGA-mPEG block copolymer with LA/GA mol ratio of 9 was designated as CP-1, a block copolymer with LA/GA mol ratio of 3 was designated as CP-2, and block copolymer with LA/GA mol ratio of 1 was designated as CP-3. The block length of each arm for all block copolymers is 1320-550. The four-arm poly( $D$,L-lactic-co-glycolic acid) (4sPLGA) copolymer was prepared as follows, take CP-1 copolymer as an example. Firstly, pentaerythritol ( $0.0015 \mathrm{~mol}, 0.204 \mathrm{~g})$, LA $(0.0505 \mathrm{~mol}, 7.27 \mathrm{~g})$, and GA $(0.0058 \mathrm{~mol}, 0.65 \mathrm{~g})$ were dried under dry nitrogen atmosphere and stirred at $100{ }^{\circ} \mathrm{C}$ for $2 \mathrm{~h}$ in a three-necked flask under vacuum. Then the temperature was increased to $160{ }^{\circ} \mathrm{C}$ for $1 \mathrm{~h}, \mathrm{Sn}(\mathrm{Oct})_{2}(0.0056 \mathrm{~g})$ was added into the melt of reactant and stirred for $6 \mathrm{~h}$. After reaction, the temperature was lowered to room temperature and acetone was added into the flask and 
precipitated with Millipore water. This purification process was repeated twice, and the product was dried by a freezing-drying method to obtain 4sPLGA copolymer. Secondly, the carboxylic mPEG was prepared. The mPEG-550 (0.006 mol, $3.30 \mathrm{~g})$ was dissolved in a $200 \mathrm{~mL}$ chloroform in a three-necked flask, SA $(0.0075 \mathrm{~mol}, 0.75 \mathrm{~g})$ and DMAP $(0.0075 \mathrm{~mol}, 0.915 \mathrm{~g})$ were added into and stirred at room temperature for $24 \mathrm{~h}$. Then, chloroform was evaporated under reduced pressure, and the residue was slowly added to saturated sodium bicarbonate solution, then extracted with ethyl acetate, the product was dried by using a freezing-drying method to obtain carboxylic mPEG. Finally, the prepared 4sPLGA copolymer, carboxylic $\mathrm{mPEG}$, and DCC $(0.006 \mathrm{~mol}, 1.238 \mathrm{~g})$ were dissolved in $200 \mathrm{~mL}$ dichloromethane in a three-necked flask, stirred at room temperature for $1 \mathrm{~h}$, then DMAP $(0.003 \mathrm{~mol}, 0.337 \mathrm{~g})$ was added to the reaction and stirred for $36 \mathrm{~h}$ at room temperature. The dicyclohexylurea as DCC hydrates was removed by suction, and then the reactant was added into diethyl ether and precipitated at $4{ }^{\circ} \mathrm{C}$ for $24 \mathrm{~h}$, this purification process was repeated twice to obtain 4sPLGA-mPEG block copolymer. A proton nuclear magnetic resonance $\left({ }^{1} \mathrm{H}\right.$ NMR) spectrometer was used to characterize the chemical composition of the prepared four-arm star-shaped block copolymers. NMR measurements were performed on a $600 \mathrm{MHz}$ NMR spectrometer (JEOL ECZ600R/S3) equipped with a $14.09 \mathrm{~T}$ superconducting magnet and a $5.0 \mathrm{~mm} 600 \mathrm{MHz}$ broadband Z-gradient high-resolution ROYAL probe (JEOL RESONANCE Inc., Japan). The molecular weight $\left(\mathrm{M}_{\mathrm{W}}\right)$ and distribution of the polymer were measured using Gel Permeation Chromatography (GPC) in an Agilent 1100 apparatus.

\subsection{Preparation of Injectable Hydrogels}

The prepared 4sPLGA-mPEG block copolymer was dissolved in simulation vaginal fluid solution (SVF, $\mathrm{pH} 4.2$, the detailed preparation of SVF solution had been described [45], Supplementary Materials, Table S1) at a concentration of $30 \mathrm{wt} \%$, and stored at $4{ }^{\circ} \mathrm{C}$. The viscosity of block copolymer solution was measured by using a Brookfield Viscometer DV-III ultra with a programmable rheometer and TC-502P temperature-controlled, programmable circulating water bath, a HA7 spindle was used, the temperature ranging from 15 to $60^{\circ} \mathrm{C}$. The prepared block copolymer solution could be transferred into hydrogels with the increase of temperature.

\subsection{Preparation of Standard Drug Solutions}

Indomethacin (IMC), gestodene (GSD), and ethinyl estradiol (EE) were accurately weighed, then dissolved in methanol and diluted to an appropriate concentration. A set of standard solutions was prepared by the appropriate dilution of the stock solution with methanol, containing $4.5-450 \mu \mathrm{g} / \mathrm{mL}$ for IMC, $1.5-150 \mu \mathrm{g} / \mathrm{mL}$ for GSD, and $0.6-60 \mu \mathrm{g} / \mathrm{mL}$ for EE. All the solutions were stored in a refrigerator at $4{ }^{\circ} \mathrm{C}$ prior to analysis.

\subsection{High-Performance Liquid Chromatography}

The concentrations of IMC, GSD, and EE for release studies in vitro were determined using the high-performance liquid chromatography (HPLC, Agilent 1100LC, USA) system, consisting of a pump and a UV-Vis detector set at 240 and $210 \mathrm{~nm}$. The analytical column was a Kromasil C18 $(4.6 \mathrm{~mm} \times 150 \mathrm{~mm})$ (Toptll technology, Wuhan, China) and the column temperature was set at $30^{\circ} \mathrm{C}$. The mobile phase consisted of methanol and water at a flow rate of $1 \mathrm{~mL} / \mathrm{min}$. An aliquot of $5 \mu \mathrm{L}$ clear supernatant was injected into the HPLC system. The peak areas of IMC, GSD, and EE were recorded, and the concentrations were calculated from the standard curve. 


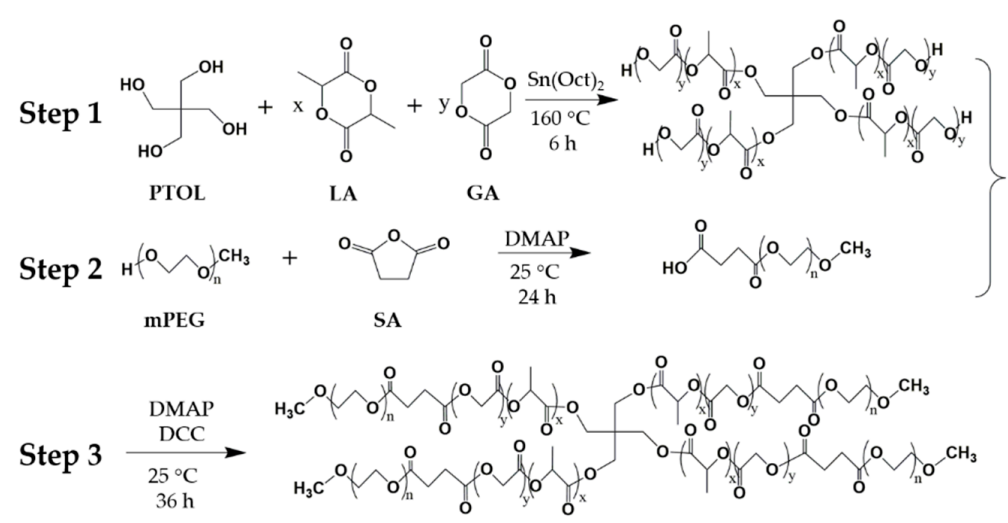

(a)

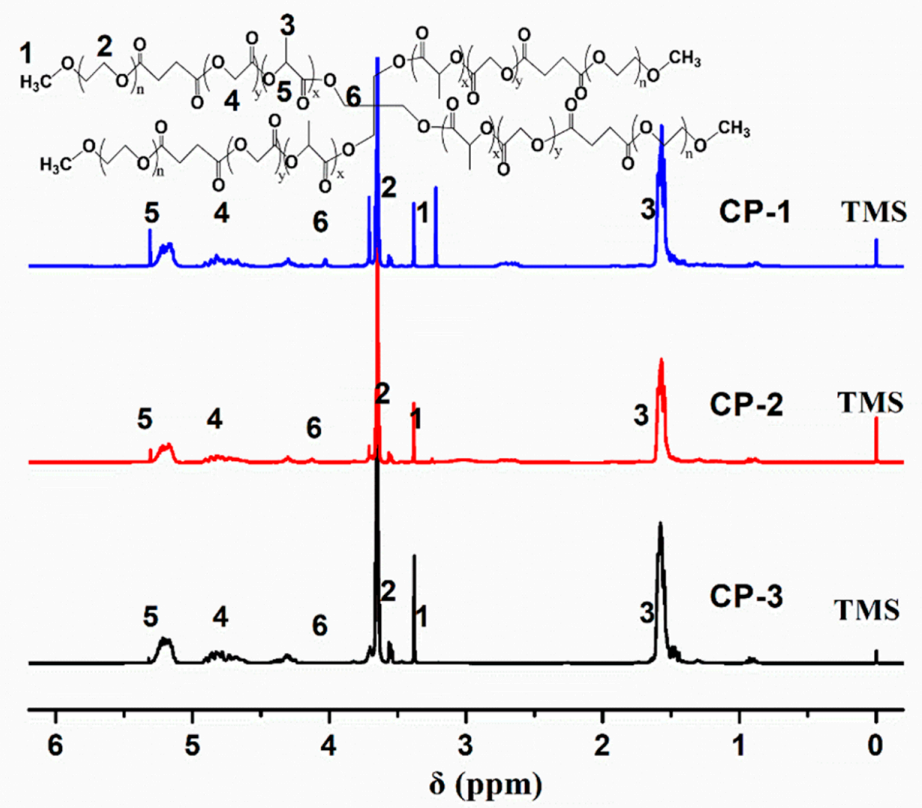

(b)

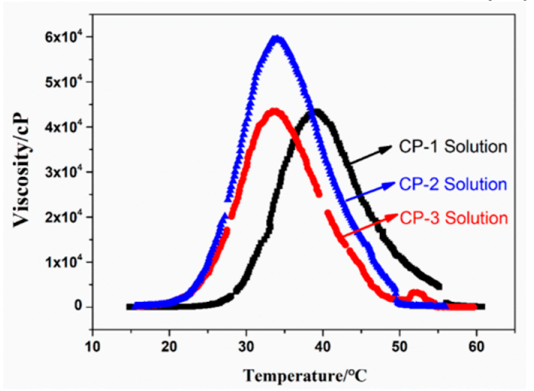

(c)

Figure 1. The preparation and characteristics of prepared poly $(D, L$-lactic-co-glycolic acid)-b-methoxy poly(ethylene glycol) (4sPLGA-mPEG) block copolymers. (a) The synthetic scheme of 4sPLGA-mPEG block copolymer, (b) ${ }^{1} \mathrm{H}$ NMR spectra of 4sPLGA-mPEG block copolymer with different LA/GA mol ratio (CP-1: $\mathrm{LA} / \mathrm{GA}=9$; $\mathrm{CP}-2$ : $\mathrm{LA} / \mathrm{GA}=3 ; \mathrm{CP}-3$ : $\mathrm{LA} / \mathrm{GA}=1)$, (c) viscosity versus temperature curves for three prepared block copolymers solutions, the copolymers were dissolved in simulation vaginal fluid solution (SVF) at the concentration of $30 \mathrm{wt} \%$. 


\subsection{Drug Release Profiles In Vitro}

Three prepared 4sPLGA-mPEG block copolymers solutions ( $30 \mathrm{wt} \%, 0.5 \mathrm{~mL}$ ) with different LA/GA mol ratios (CP-1, CP-2, and CP-3) and some amounts of IMC, GSD, EE were injected into vials and incubated in a shaking bath at $37^{\circ} \mathrm{C}$. Three groups of each drug content were designed in this experiment, as shown in Table 1 . After $1 \mathrm{~min}, 10 \mathrm{~mL}$ of SVF solution containing $0.05 \mathrm{wt} \%$ Tween 80 and $0.025 \mathrm{wt} \%$ sodium azide was added to the formed temperature-sensitive hydrogel and vials were shaken at 50 strokes $/ \mathrm{min}$. At predetermined times, some samples were collected and centrifuged at $3000 \mathrm{rpm}$ for $5 \mathrm{~min}$. An aliquot of $1 \mathrm{~mL}$ supernatant was taken and replaced with an equal amount of fresh SVF solution. The supernatant was then centrifuged at 10,000 rpm for $10 \mathrm{~min}$. The supernatant solution was filtrated through a syringe filter $(0.45 \mu \mathrm{m})$. The amount of IMC, GSD, and EE in the collected supernatant was measured by HPLC. All release tests were performed in triplicate.

Table 1. Different groups with different drug content for investigating in vitro release profiles of indomethacin (IMC), gestodene (GSD), and ethinyl estradiol (EE).

\begin{tabular}{ccc}
\hline Group & Drug & Content $(\mathrm{mg} / \mathrm{mL})$ \\
\hline High Dosage Content & IMC & $22.5 \pm 0.7$ \\
High Dosage Content & GSD & $9.5 \pm 0.2$ \\
High Dosage Content & EE & $3.6 \pm 0.2$ \\
Middle Dosage Content & IMC & $11.6 \pm 0.6$ \\
Middle Dosage Content & GSD & $4.85 \pm 0.35$ \\
Middle Dosage Content & EE & $2.0 \pm 0.3$ \\
Low Dosage Content & IMC & $5.5 \pm 0.2$ \\
Low Dosage Content & GSD & $2.25 \pm 0.35$ \\
Low Dosage Content & EE & $0.9 \pm 0.6$ \\
\hline
\end{tabular}

\subsection{Animals Experiments}

All animal experiments were performed in accordance with the Animal Ethical Committee of Wuhan Hanyang Hospital (Permit number 00027346). Female Sprague-Dawley (SD) rats (330-350 g, SPF, provided by Wuhan University of Science and Technology Animal Center) were used in the experiments. All animals were treated according to the "Principles of Laboratory Animal Care" (NIH publication \#85-23, revised 1985). Every five SD rats were housed in stainless steel cages containing sterile sawdust as bedding in ventilated animal rooms. They were acclimated in the controlled environment (temperature: $22 \pm 1{ }^{\circ} \mathrm{C}$; humidity: $60 \pm 10 \%$ and light: $12 \mathrm{~h}$ light/dark cycle) with free access to water and a commercial laboratory complete food. SD rats were injected intravaginally with 4-arm star-shaped PLGA-mPEG hydrogels (4s-1320-550, LA/GA mol ratio = 1, and copolymer concentration was $30 \mathrm{wt} \%$ in hydrogel) at various loading drug dose levels as follows: high dose group (IMC $900 \mu \mathrm{g} / \mathrm{mL}, \mathrm{GSD} 250 \mu \mathrm{g} / \mathrm{mL}$ and EE $100 \mu \mathrm{g} / \mathrm{mL}$ ), medium dose group (IMC $450 \mu \mathrm{g} / \mathrm{mL}$, GSD 130 $\mu \mathrm{g} / \mathrm{mL}$ and EE $50 \mu \mathrm{g} / \mathrm{mL}$ ), and low dose group (IMC $230 \mu \mathrm{g} / \mathrm{mL}$, GSD $70 \mu \mathrm{g} / \mathrm{mL}$ and EE $30 \mu \mathrm{g} / \mathrm{mL}$ ). The injection volume was $0.2 \mathrm{~mL}$. Vaginally injections of star-shaped PLGA-mPEG hydrogels without loading three drugs were also given to SD rats as a control group. On day 1, 3, and 5 after the last injection, the rats were sacrificed, and organs were recovered.

\subsection{Histopathological Examinations}

A portion of tissues (heart, liver, spleen, lung, kidney, uterus, and vagina) were cut out and immediately fixed in a $10 \%$ formalin solution. Histopathological test was performed using standard laboratory procedures. Tissues were embedded in paraffin blocks, then sectioned into $5 \mu \mathrm{m}$ sections and mounted onto glass slides. After hematoxylin-eosin staining, slides were observed and photos were taken using an optical microscope (Olympus X71, Japan). All the identity and analysis of the pathology slides were blind to the pathologist. 


\subsection{Determination of Estrous Cycle}

The phase of the estrous cycle was determined by vaginal cytology investigating epithelial cells collected from the vaginal wall by a cotton swab dampened with saline. All samples were collected daily from approximately $1200-1300 \mathrm{~h}$ and immediately examined under a $100 \times$ magnification microscope. SD rats with a majority of cornified epithelial cells was considered to be in estrus; rats with a mix of cornified epithelial cells, nucleated epithelial cells, and leukocytes were considered to be in metestrus; rats with a majority of leukocytes were considered to be in diestrus; and, rats with a majority of nucleated epithelial cells were considered to be in proestrus. Rats with exhibiting an irregular estrous cycle were excluded from the experiment.

\subsection{Antifertility Experiment}

Proestrus SD female rats were mated with male rats of proven fertility ( 2 females $\times 1$ male) after injecting drug-loaded copolymer hydrogels with low dose group (IMC: $230 \mu \mathrm{g} / \mathrm{mL}$, GSD: $70 \mu \mathrm{g} / \mathrm{mL}$ and EE: $30 \mu \mathrm{g} / \mathrm{mL}$ ) into the vagina. Simultaneously, copolymer hydrogels without packing drug were also operated as blank control. Successful mating was assessed by daily vaginal smear examination. In our investigation, the mating time happened for all SD female rats in 1 day after injection. The day on which sperms were found was designated as the first day of pregnancy. At day 15, the doctor will check the pregnancy outcome of animals.

\subsection{Statistics}

All data were expressed as means with standard deviation. Analyses utilized SPSS software (SPSS Inc, Chicago IL). Statistical analyses were performed by ANOVA or 2-way repeated measures ANOVA with Tukey's test applied to investigate specific differences. Statistical significance was defined as a $p$-value of $<0.05$ for $95 \%$ confidence.

\section{Results}

\subsection{Characterization of 4sPLGA-mPEG Block Copolymers}

The chemical structure of prepared 4sPLGA-mPEG block copolymers was characterized by ${ }^{1} \mathrm{H}$ NMR spectra as shown in Figure 1b. The signal at 3.38 ppm was assigned as the terminal methoxy proton of $\mathrm{mPEG}$, signals at 3.65 and $4.30 \mathrm{ppm}$ were due to the methylene proton. The methoxy proton signal of LA units in PLGA segments at $\delta=1.55 \mathrm{ppm}$, and the methyne proton signal at $\delta=5.20 \mathrm{ppm}$, and for GA units, the signal at $4.82 \mathrm{ppm}$ was assigned to methylene proton. In addition, proton signal at $2.66 \mathrm{ppm}$ was due to the methylene proton of SA units and signal at $4.21 \mathrm{ppm}$ was in correspondence with the methylene proton of PTOL units. The molecule weight $\left(\mathrm{M}_{n}\right)$ of $\mathrm{CP}-1, \mathrm{CP}-2$, and CP-3 measured by GPC were 7610, 7690, and 7640 Da respectively, which were close to the theoretical molecule weight of block copolymer ( $8010 \mathrm{Da}$ ) (Figure S1). The prepared block copolymer was dissolved in SVF solution at a concentration of $30 \mathrm{wt} \%$, the sol-gel transition was measured by using viscosity test as a function of temperature, as shown in Figure 1c. For the three block copolymer solutions (CP-1, CP-2, and CP-3), the viscosities increased sharply with increasing temperature, confirmed the sol-gel phase transition. The sol-gel transition temperature ranges from about 25 to $30^{\circ} \mathrm{C}$. The sol-gel transition temperature of 4sPLGA-mPEG block copolymer solution depended on the LA/GA mol ratio, and with the increase of LA/GA mol ratio, the gel transition temperature increased, and the body temperature was in the gel phase for all three copolymers. With further increasing temperature, the viscosities of the copolymer solutions dropped abruptly, indicating the gel-sol phase transition.

\subsection{Determination of HPLC Condition}

Different from single-drug release profile measurement, the suitable HPLC condition for testing multi-drug release profile need to be further investigated. The UV-Vis spectra of IMC, GSD, and EE were recorded using HPLC with a UV-Vis detector from 180 to $400 \mathrm{~nm}$ to determine the maximum absorption wavelengths of these three drugs (Figure 2a). The maximum absorption peaks of IMC 
and EE were $\sim 210 \mathrm{~nm}$, and the maximum absorption peak of GSD was $\sim 240 \mathrm{~nm}$. These maximum absorption wavelengths corresponding with IMC, GSD, and EE were used to improve accuracy. HPLC curves for mixed drugs at various volume ratios of methanol and water were shown in Figure $2 \mathrm{~b}$. A good separation of mixed drugs was observed at a volume ratio of optimal mobile phase with 53:47. Comparing the HPLC curve of three mixed drugs with one of a single drug, the retention time of IMC, GSD, and EE were 11.18, 13.11, and 15.57 min, respectively, as shown in Figure 2c.

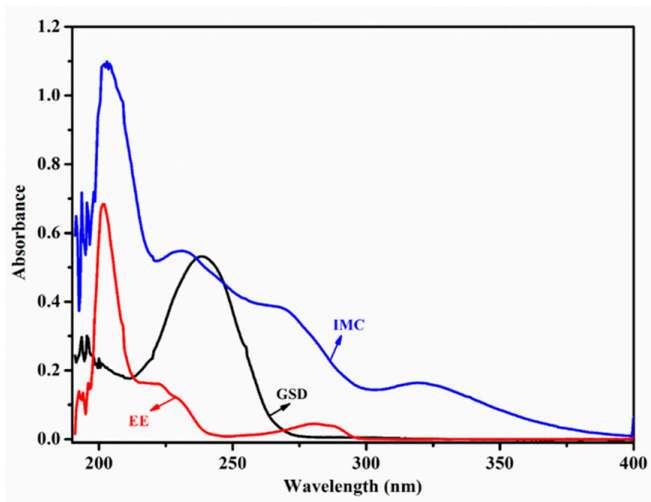

(a)

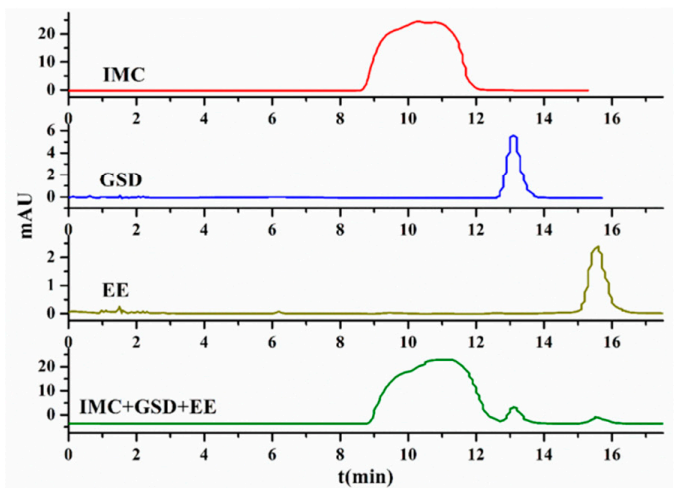

(c)

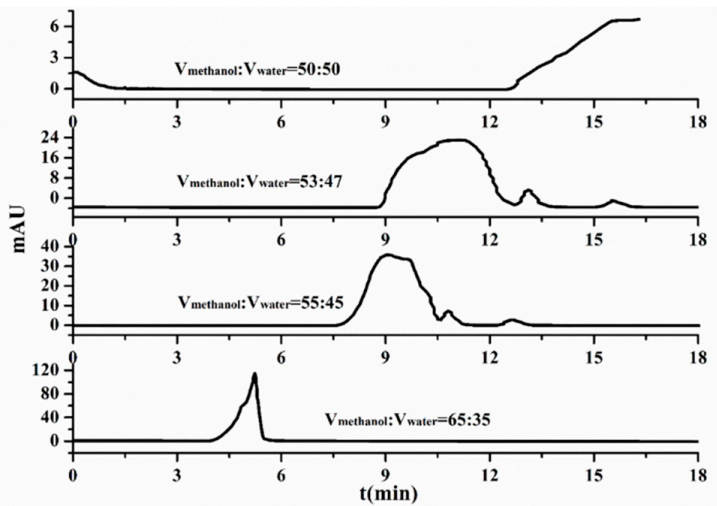

(b)

Figure 2. (a) The UV-Vis spectra of indomethacin (IMC), gestodene (GSD), and ethinyl estradiol (EE) were recorded using HPLC with a UV-Vis detector from 180 to $400 \mathrm{~nm}$, (b) HPLC curves of IMC, GSD and $\mathrm{EE}$ in methanol at various mixture ratios of methanol and water, (c) HPLC curves of IMC, GSD, EE, and their mixture (methanol/water ratio is $53: 47$ ).

Linear calibration curves were constructed by six concentration assays of each reference compound in triplicate. The regression equation was calculated in the form of $y=a x+b$, where $y$ and $x$ were the values of peak area and concentration of each reference compound, respectively. Results of the regression equations were shown in Figure S2, and the correlation coefficients $\left(R^{2}\right)$ were all over 0.998 . The high correlation coefficient values indicated good linearity between their peak areas $(y)$ and investigated compound concentrations $(x)$ in relatively wide concentration ranges.

\subsection{In Vitro Drug Release Profiles}

The drug release profile was mainly depended on the degradable properties of the copolymer, and the lactide/glycolide (LA/GA) mol ratio had a markedly influence on degradability of star-shaped PLGA-mPEG copolymer hydrogel, which was reported in our previous papers [44,46]. The release profiles of IMC, GSD, and EE from star-shaped PLGA-mPEG copolymer hydrogels with different LA/GA mol ratios were first investigated here. Figure 3 showed cumulative release profiles of three mixed drugs packed by star-shaped PLGA-mPEG copolymer hydrogels with the same drug content (middle) and various LA/GA mol ratios in PLGA blocks at the previously defined days. Cumulative 
release amount of IMC, GSD, and EE in copolymer hydrogels increased with the decrease of LA/GA mol ratio from 9 to 1 . In other words, better degradability of copolymer hydrogels with lower LA/GA mol ratios gave rise to a faster release of three drugs. The drug release rate might be mainly controlled by drug diffusion and degradability of copolymer hydrogels, the released amounts of drugs from hydrogels with different LA/GA mol ratios were obviously different in one month, as shown in Figure S3a-c.

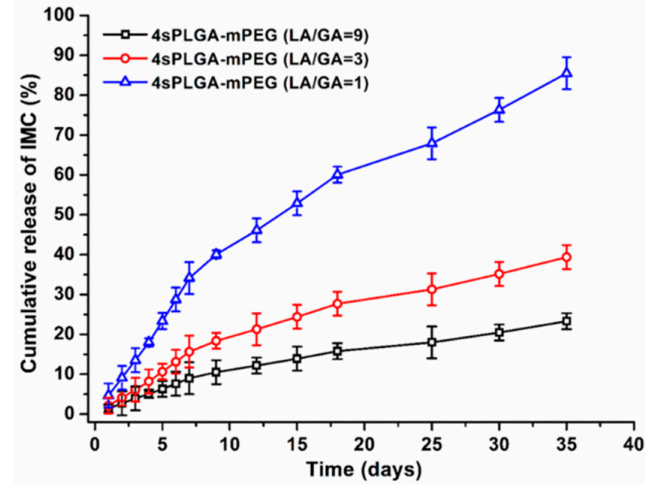

(a)

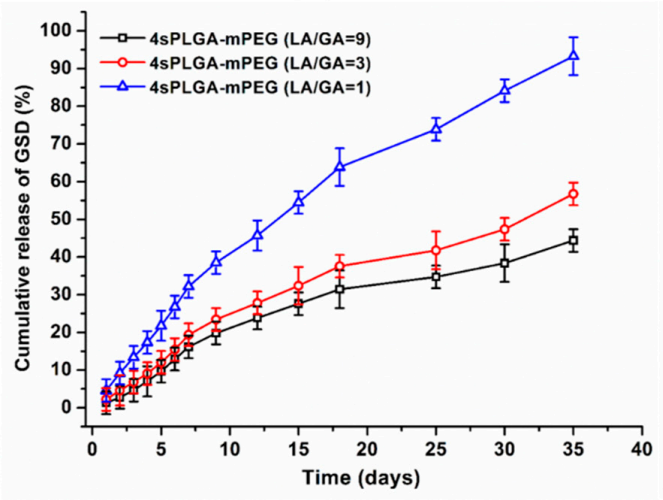

(c)

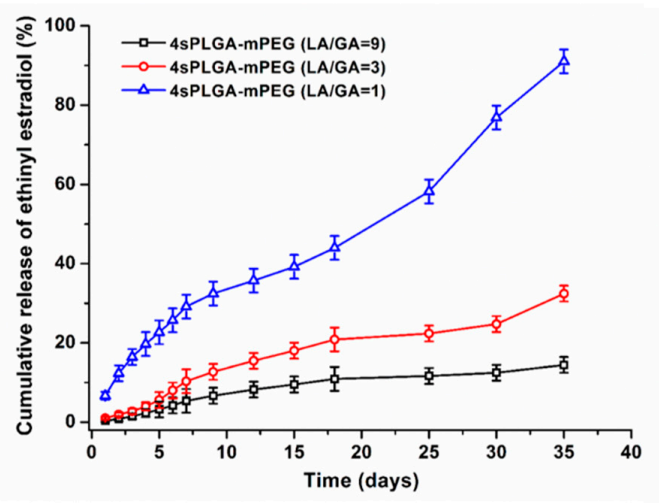

(e)

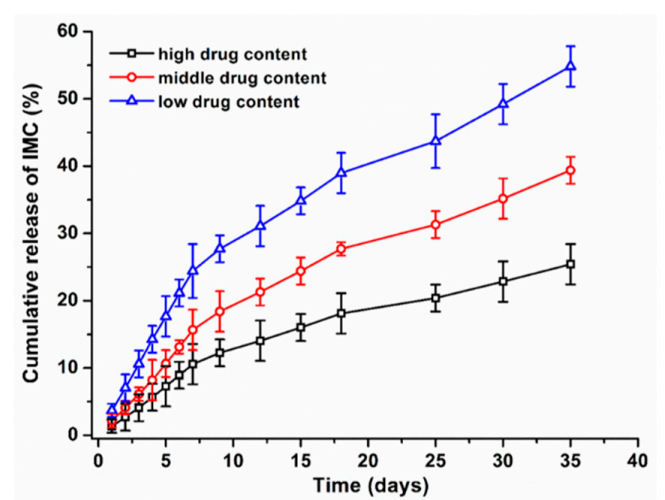

(b)

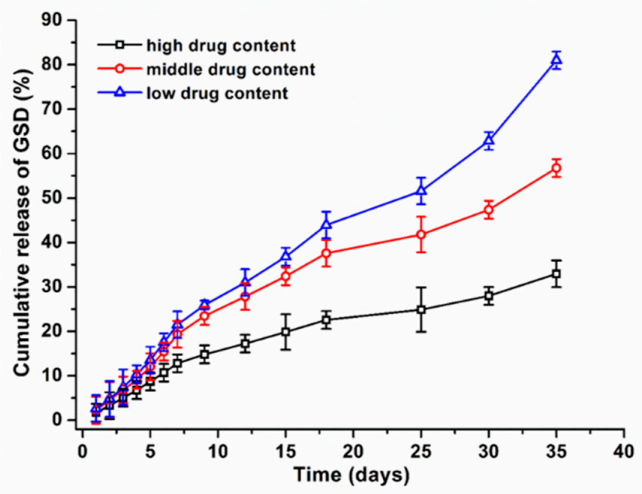

(d)

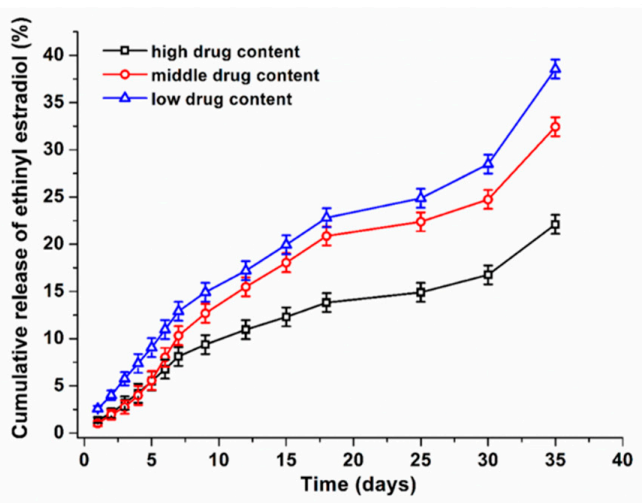

(f)

Figure 3. The release profiles of indomethacin (IMC), gestodene (GSD), and ethinyl estradiol (EE) from prepared 4sPLGA-mPEG block copolymer hydrogels. Cumulative release of IMC (a), GSD (b), and EE (c) packed by copolymer hydrogel with the same middle drug content and various lactide/glycolide (LA/GA) mol ratios. Cumulative release of IMC (d), GSD (e), and EE (f) loaded by CP-2 copolymer $(\mathrm{LA} / \mathrm{GA}=3)$ hydrogel with various drug contents (high, middle, and low). Copolymer concentration was $30 \mathrm{wt} \%$. 
On the other hand, the release amount and cumulative release profiles of three mixed drugs from CP-2 copolymer hydrogels loaded with various drugs contents (high, middle, and low) were studied, and the results were shown in Figure S3d-f and Figure 3. With the increase of drug content in CP-2 copolymer hydrogel, the release amount of IMC and GSD were also higher at different days, however, the cumulative release of IMC and GSD increased faster with the decrease of drug loading amount. For EE release profile, the loading content had a slight influence on the release amount from CP-2 copolymer hydrogels (Figure S3f), and the cumulative EE release profiles still increased faster with the decrease of initial EE loading amount.

Synchronic release profiles of three drugs were fitted by three drug release models, namely, zero-order, first-order and Higuchi model. Table S2 listed all fitting parameters using above-mentioned drug kinetic models. The high correlation coefficient $\left(R^{2}\right)$ values and good linear relation of fitting curves by Higuchi model, indicated that release profiles of IMC, GSD, and EE were well fitted with Higuchi model. Take the cumulative release of GSD from CP-3 copolymer hydrogel (LA/GA = 1) as an example, the fitting curve was shown in Figure S4, the correlation coefficient was 0.996.

\subsection{In Vivo Acute Toxicity of Copolymer Hydrogels with Loading Multi-drug}

Figure 4 showed photographs of SD rats at indicated days after injecting hydrogels with different mixed drug dosages into the vagina. For the control group (injected hydrogels without drugs), no significant tissue necrosis was found on dates specified throughout our observation. This result was consistent with our previously reported paper $[40,44]$, which used a subcutaneous injection into the neck of SD rats instead of injecting into the vagina and, confirmed a good biocompatibility of star-shaped PLGA-mPEG copolymer hydrogel as drug carrier. For the high dosage group, slight hydroncus of the uterus was observed on day 1 . The swelling of uterus became extremely serious and intestinal adhesion was also found at day 3. Uterus and intestines ulcerated at day 5. With regarding the middle dosage group, no fester of tissues was observed, and blood coagulum existed in the uterus at a different defined time. For the low dosage group, no significant tissue necrosis was found from day 1.

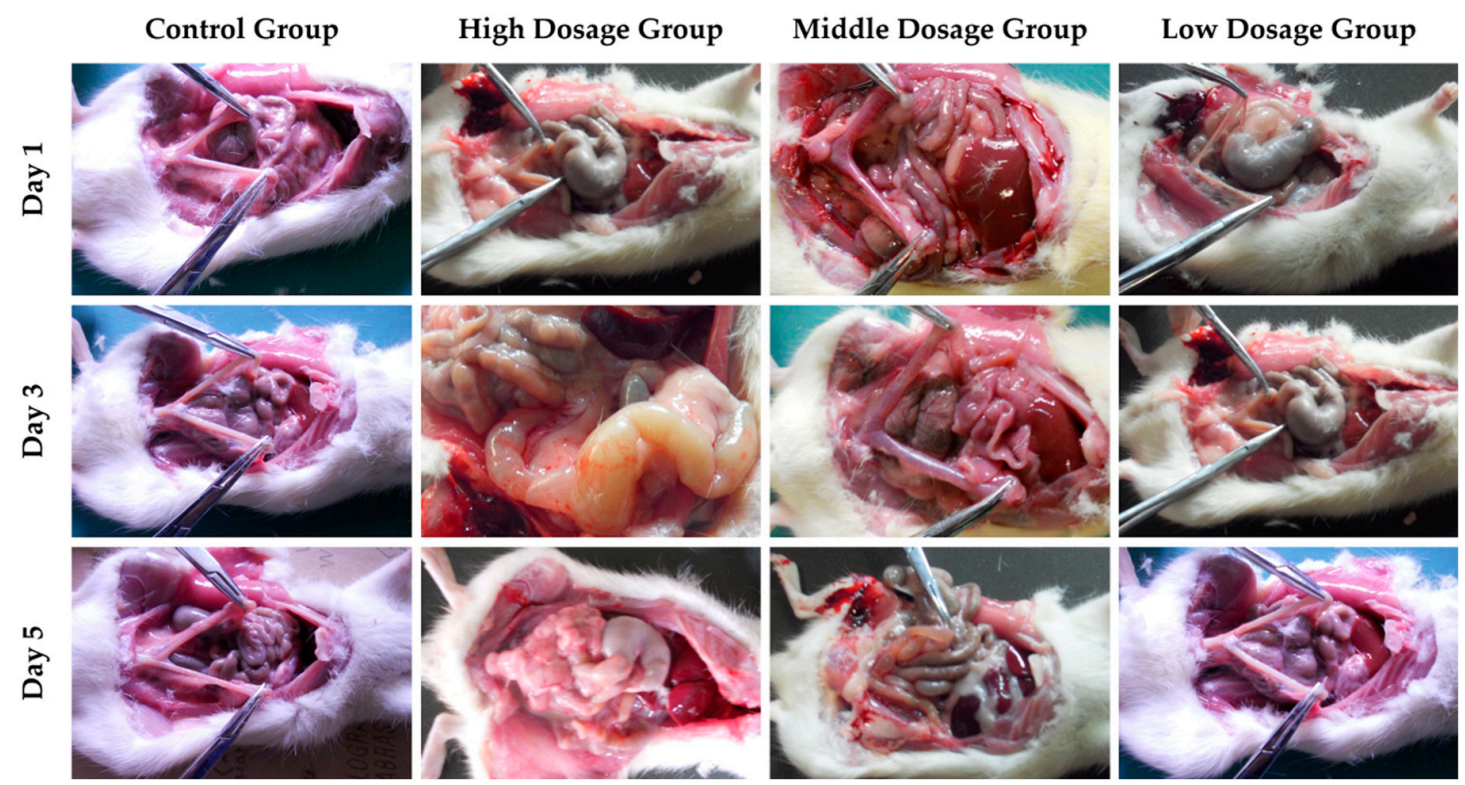

Figure 4. Photographs of Sprague-Dawley (SD) rats at various indicated days after injecting hydrogels loading with different drug dosages into the vagina (high dosage, middle dosage, and low dosage). The CP-3 block copolymer solution at the concentration of $30 \mathrm{wt} \%$ was used. The volume of drug-loaded copolymer solution injected into the vagina is $0.2 \mathrm{~mL}$. Copolymer solutions without loading drug were injected into the vagina of SD rats as a control group. 
In the control group, liver sections showed normal hepatic cells with well-preserved cytoplasm, prominent nucleus and nucleolus, and central vein, as shown in Figure 5. No abnormalities were observed in liver organs in the low dosage and middle dosage group. However, on day 3 and day 5 hepatocytes necrosis exhibiting pale cytoplasm color with an unclear interface and lymphocytic infiltration in liver were observed in high dosage group, suggested that copolymer hydrogels packed higher dose was toxic to the hepatic organ [47].

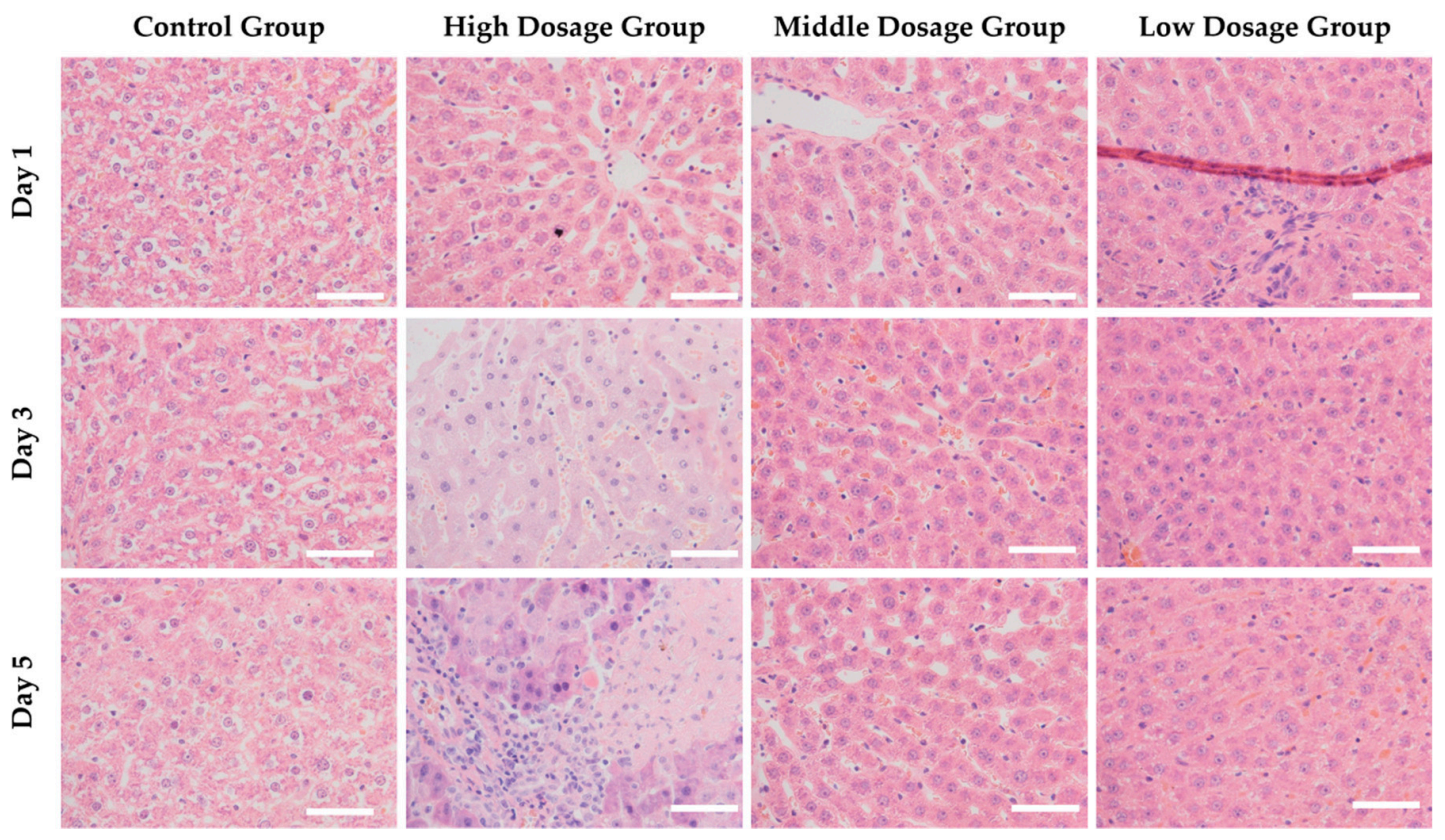

Figure 5. Hematoxylin-eosin (HE) staining of Sprague-Dawley (SD) rat livers at various indicated days after injecting hydrogels with different drug dosages into the vagina (high dosage, middle dosage, and low dosage). The CP-3 block copolymer solution at the concentration of $30 \mathrm{wt} \%$ was used. The volume of drug-loaded copolymer solution injected into the vagina is $0.2 \mathrm{~mL}$. Copolymer solutions without loading drug were injected into the vagina of SD rats as a control group, scale bar: $5 \mu \mathrm{m}$.

Figure 6 showed the HE staining of uterus sections at various indicated days after injecting hydrogels with different mixed drug dosages into the vagina. In the control and low dosage group, no lesion was found in the uterus. Endometrium was composed of a cylindrical epithelium with basally located nuclei which lined both the uterine lumen and glands and lamina propria is densely packed [48]. As to the middle dosage group, epithelial hyperplasia was presented in almost all animal samples, and uterus congestion was found at day 3 . In the high dosage group, extremely severe swelling of the cylindrical epithelium of uterus was observed at day 1,3, and 5 .

Figure 7 showed the HE staining of vagina sections at the various indicated time after injecting hydrogels with different mixed drug dosages into the vagina. In the vagina, no histological changes were observed in the control and low dosage group. Squamous cell hyperplasia was prominent in the middle dosage group [49]. However, in the high dosage group, vaginal bleeding was found at all indicated times.

The histological photomicrographs of the spleen sections were shown in Figure 8. No severe damages of spleen tissue were reflected in the control and the low dosage group, while lymph nodule proliferation was observed in the middle and high dosage group [50]. In addition, there were no abnormal pathology changes in the heart, lung and kidney tissues, as shown in Figures S5-S7. 


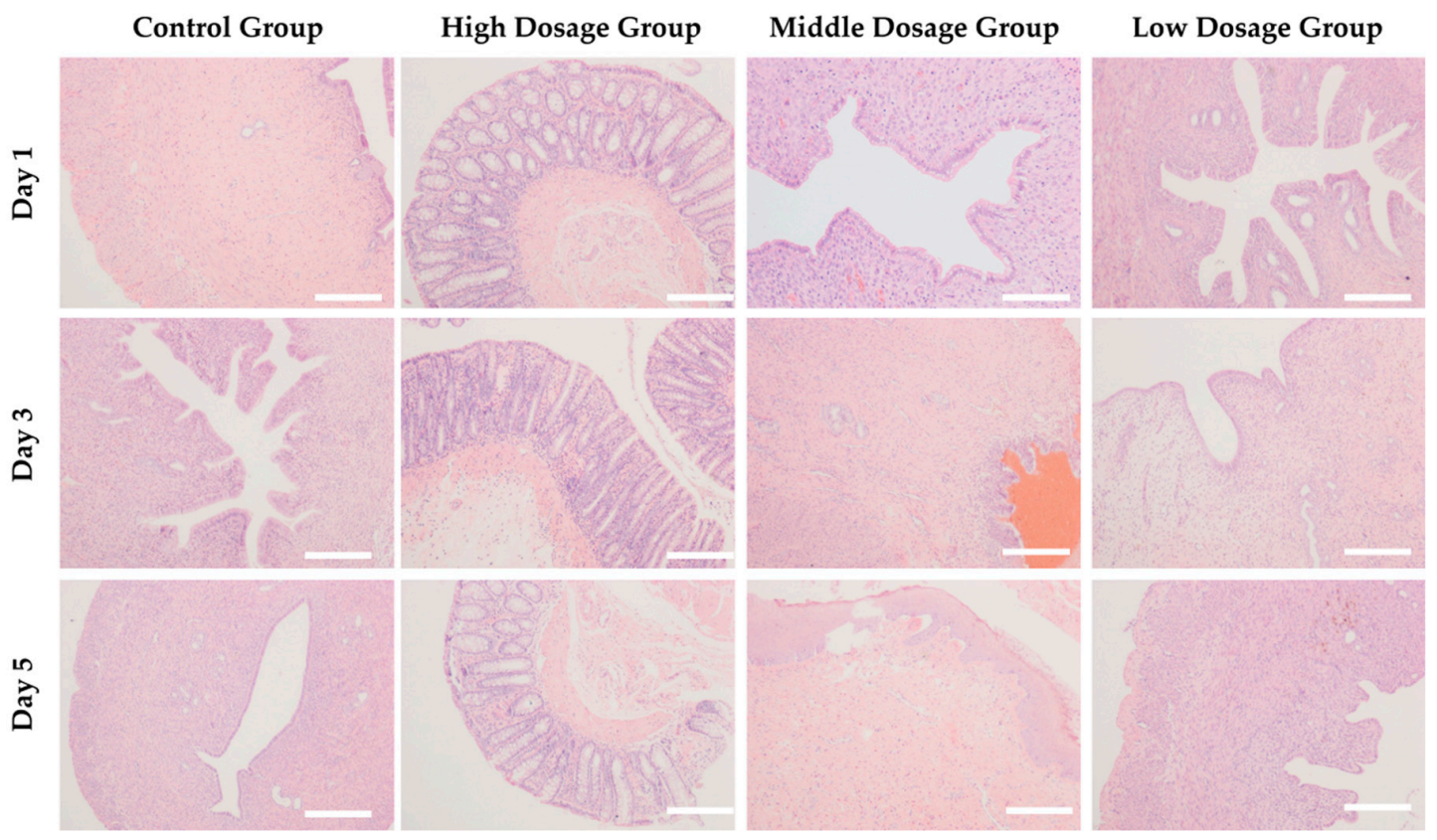

Figure 6. Hematoxylin-eosin (HE) staining of Sprague-Dawley (SD) rat uterus at various indicated days after injecting hydrogels with different drug dosages into the vagina (high dosage, middle dosage, and low dosage). The CP-3 block copolymer solution at the concentration of $30 \mathrm{wt} \%$ was used. The volume of drug-loaded copolymer solution injected into the vagina is $0.2 \mathrm{~mL}$. Copolymer solutions without loading drug were injected into the vagina of SD rats as a control group, scale bar: $20 \mu \mathrm{m}$.

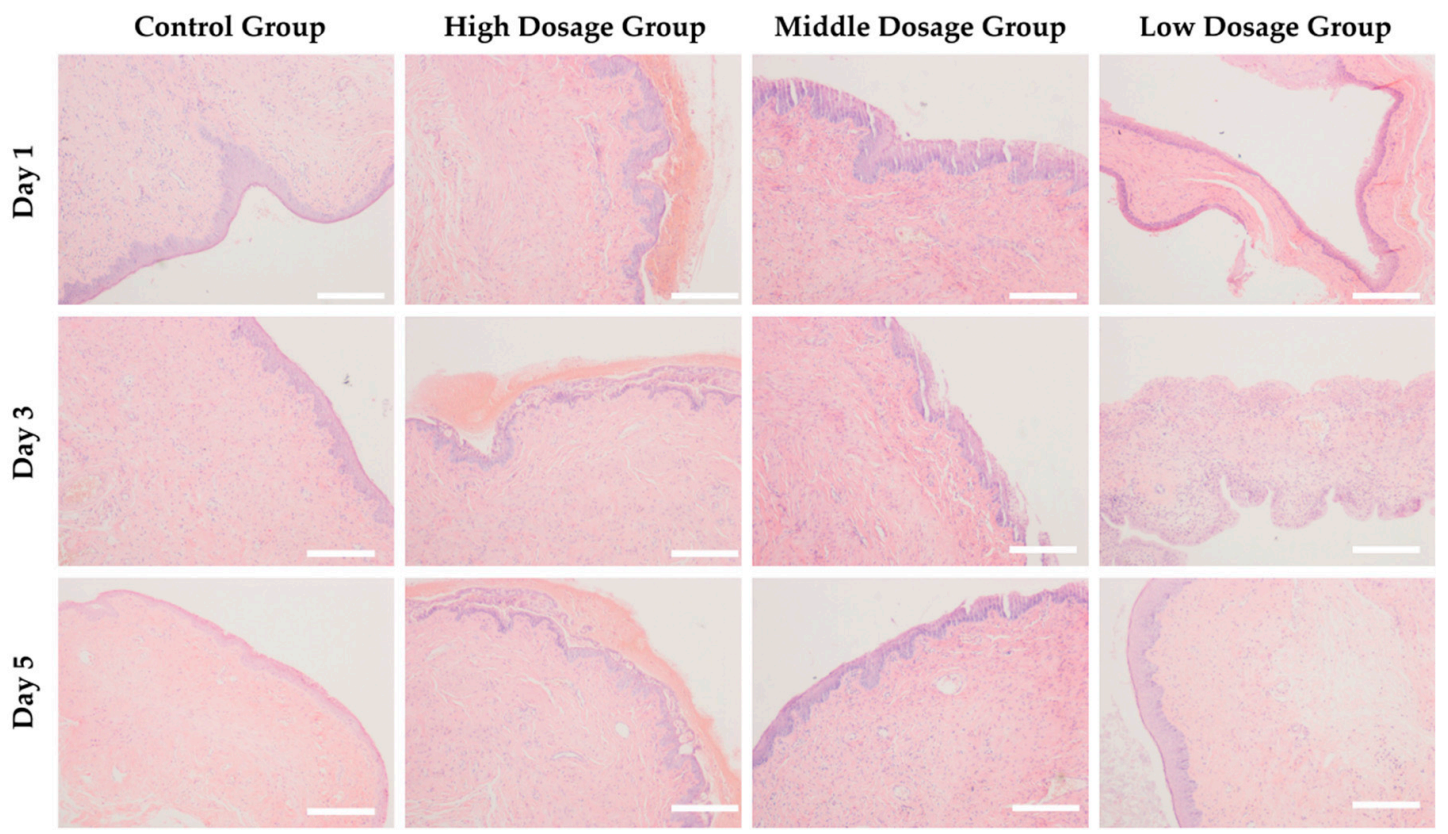

Figure 7. Hematoxylin-eosin (HE) staining of Sprague-Dawley (SD) rat vagina at the various indicated time after injecting hydrogels with different drug dosages into the vagina (high dosage, middle dosage, and low dosage). The CP-3 block copolymer solution at the concentration of $30 \mathrm{wt} \%$ was used. The volume of drug-loaded copolymer solution injected into the vagina is $0.2 \mathrm{~mL}$. Copolymer solutions without loading drug were injected into the vagina of SD rats as a control group, scale bar: $20 \mu \mathrm{m}$. 

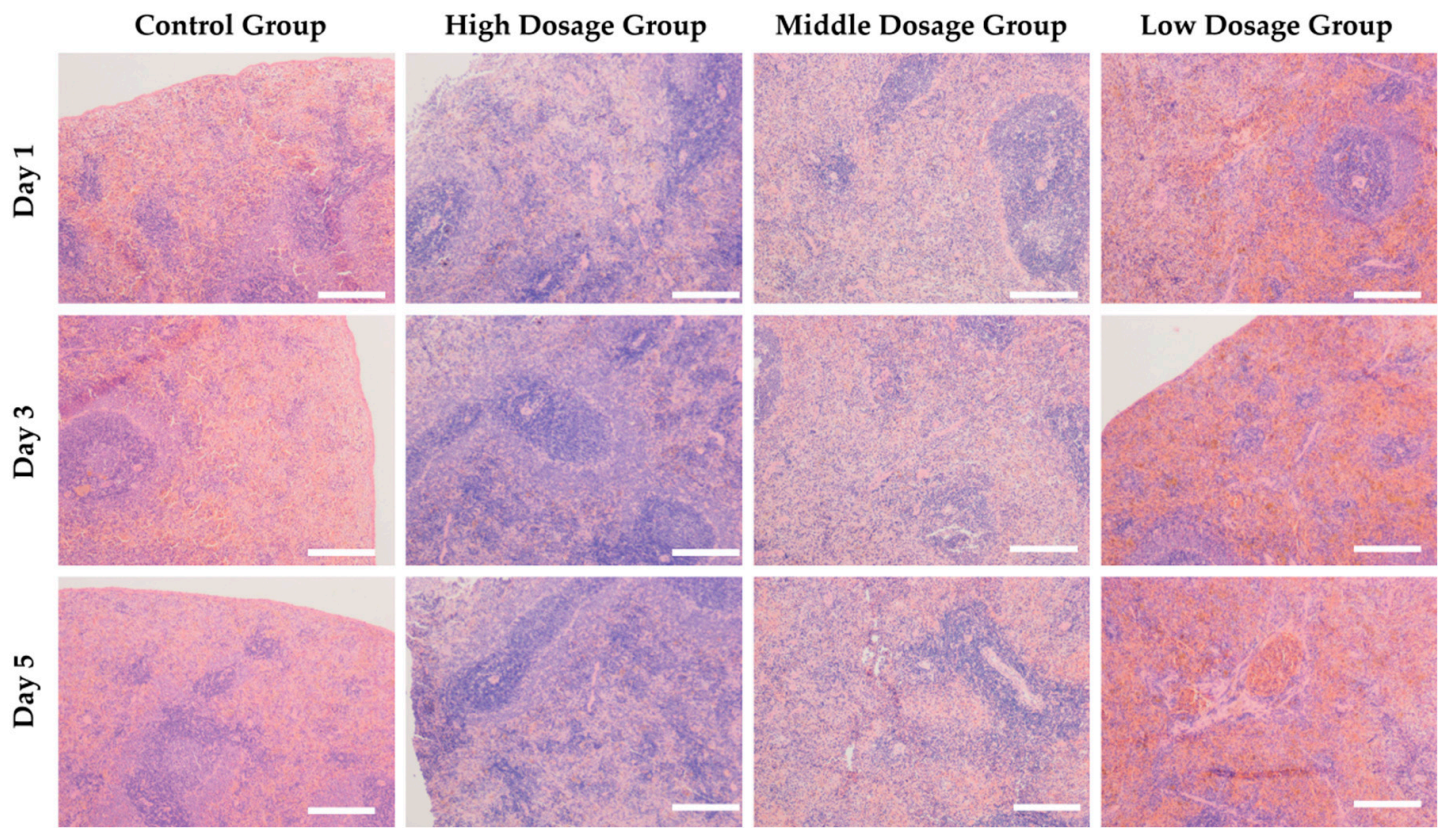

Figure 8. Hematoxylin-eosin (HE) staining of Sprague-Dawley (SD) rat spleen at various indicated days after injecting hydrogels with different drug dosages into the vagina (high dosage, middle dosage, and low dosage). The CP-3 block copolymer solution at the concentration of $30 \mathrm{wt} \%$ was used. The volume of drug-loaded copolymer solution injected into the vagina is $0.2 \mathrm{~mL}$. Copolymer solutions without loading drug were injected into the vagina of SD rats as a control group, scale bar: $20 \mu \mathrm{m}$.

\subsection{Antifertility Evaluation}

Figure 9 showed the results of the antifertility experiment as female SD rats were used in this paper and CP-3 block copolymer hydrogel loading low drug dosage was injected into the vagina. Normal embryos were detected in the control group and the pregnancy rate was $100 \%$. Interestingly, no embryo was observed in the drug-loaded hydrogel group, indicating that the copolymer hydrogel system with packing drugs was feasible as a novel contraception method. For the drug-unloaded gel group, a $60 \%$ pregnancy rate suggested that hydrogel material could affect the fertility of female SD rats.

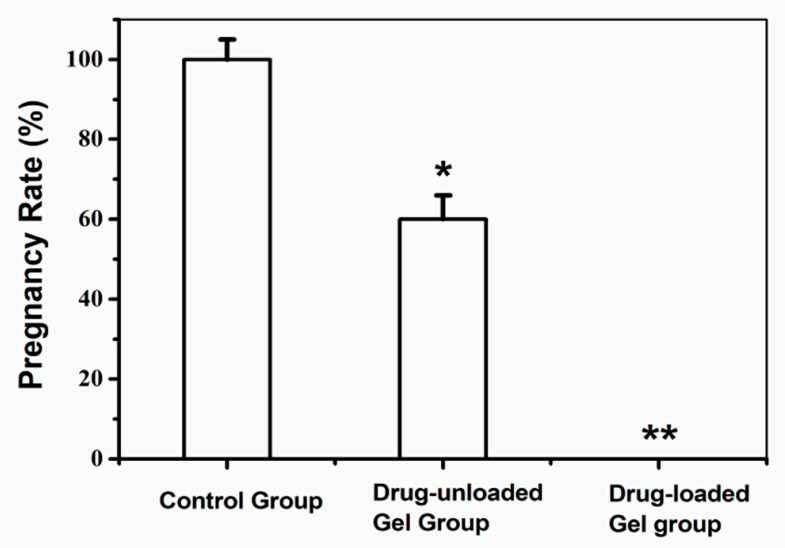

Figure 9. The pregnancy rate of female Sprague-Dawley (SD) rats treated with CP-3 block copolymer hydrogels loaded with Indomethacin (IMC), Gestodene (GSD), and Ethinyl Estradiol (EE) mixed drugs (low dosage) and bare CP-3 block copolymer hydrogels, the SD rats without injected hydrogels as a control group. The concentration of copolymer was $30 \mathrm{wt} \%$, the volume of drug-loaded copolymer solution injected into the vagina is $0.2 \mathrm{~mL} .{ }^{* *} p<0.01,{ }^{*} p<0.05$. 


\section{Discussion}

It was reported that the world's population would reach 9 10 billion by 2050, the population explosion has become the principal reason for environmental dilapidation with following human poverty and starvation [51]. Controllable unintended pregnancy effectively prevented the increase of population to a certain extent. Nowadays, the characteristics of easy-to-use and multifunctionality are more important factors considered by users for contraception [52], and long-acting contraceptive implants become available to improve family planning services [53]. The thermosensitive hydrogels of a suitable gelation temperature have potentials on the local vaginal site delivery system $[54,55]$. The thermo-gelling star-shaped PLGA-mPEG copolymers comprising hydrophobic biodegradable and hydrophilic biocompatible segments are of particular interest to drug delivery systems and tissue engineering applications. In this paper, the four-arm star-shaped 4sPLGA-mPEG copolymer hydrogels were used as a multi-contraceptive carrier. The in vitro controlled release profiles, in vivo acute toxicity, and antifertility effectivity were systematically reported.

In our previous works, the four-arm star-shaped 4sPLGA-mPEG copolymer was synthesized via the arm-first method $[44,46]$. Here, the copolymer was prepared by a core-first method. Compared to the arm-first method, the same number of steps were used during the synthesis, and the same chemical structure was obtained characterized via ${ }^{1} \mathrm{H}$ NMR analysis (Figure 1b). The prepared 4sPLGA-mPEG copolymer was dissolved in SVF solution instead of Millipore water, and the sol-gel transition behavior as a function of temperature from $15^{\circ} \mathrm{C}$ to $60^{\circ} \mathrm{C}$ was tested by the viscometer. It was known that the sol-gel behavior of thermosensitive copolymer was susceptive to environmental changes, such as $\mathrm{pH}$ or chemicals [56,57]. The $\mathrm{pH}$ of the SVF solution is about 4.2 , the sodium chloride, potassium hydroxide, lactic acid, and acetic acid in SVF solution might influence the gelation temperature of the prepared copolymer. Interestingly, the gel transition temperature of 4sPLGA-mPEG copolymer dissolved in SVF was mainly decided by LA/GA ratio, and chemicals in SVF solution and $\mathrm{pH}$ of SVF solution both had a slight influence on gelation temperature. The star-shaped 4sPLGA-mPEG block copolymers with the hydrophobic PLGA blocks and the hydrophilic mPEG blocks were amphiphilic. For CP-1, CP-2, and CP-3 block copolymers in solution (SVF or water) at a suitable concentration (30 wt\%), with temperature increased, the copolymers could form multimolecular micelles, then micellar aggregated to accomplish the sol-gel transition (Figure S8) [58]. With the increase of LA units in block copolymers, the gelation temperature increased, as confirmed in Figure 1c. The packing interaction between micelles was achieved to an optimal dense (hydrogel state) at a suitable temperature, which makes such hydrogel easy for drug encapsulation and biomedical applications, as shown in Scheme 1.

The prepared star-shaped 4sPLGA-mPEG copolymer hydrogel was used as a carrier for delivering three hormonal contraceptives, indomethacin (IMC), gestodene (GSD), and ethinyl estradiol (EE). The multi-drug release profiles could be measured via HPLC by using an optimal mobile phase of methanol/water volume ratio at 53:47. Regarding the retention time of IMC, GSD, and EE are 11.18, 13.11 , and $15.57 \mathrm{~min}$ respectively, and the UV-vis recording of the maximum absorption peaks (IMC and EE at $\sim 210 \mathrm{~nm}, \mathrm{GSD}$ at $\sim 240 \mathrm{~nm}$ ), and the release profiles of IMC, GSD, and EE were calculated. For three drugs release profiles, it was observed that a higher release rate was presented in the initial 7 days, and the release rate became relatively slower from 7 to 35 days, as shown in Figure 3 and Figure S4. The drug released from hydrogel might be mainly controlled by drugs' diffusion and the degradability of copolymer hydrogel during the first week, after then, the degradability of copolymer hydrogel became the main factor to regulate drug release profiles. The biodegradation rate of star-shaped 4sPLGA-mPEG copolymer hydrogel could be regulated by LA/GA mol ratio. In addition, the acid environment of the vagina could urge the degradation of prepared block copolymer hydrogels, mainly due to the break of ester bonds in block copolymers. The degradable mechanism of the star-shaped 4sPLGA-mPEG copolymer was shown in Scheme 2. In brief, the degradation process of the copolymer was divided into the following three steps. In the first step, the ester bond linked with the mPEG blocks preferentially hydrolyzed and the composition of PLGA segments were invariant. In the second step, 
the GA units in the PLGA blocks and the ester bonds linked with the mPEG blocks mainly hydrolyzed. In the final step, the LA units in the PLGA blocks mainly hydrolyzed [46].

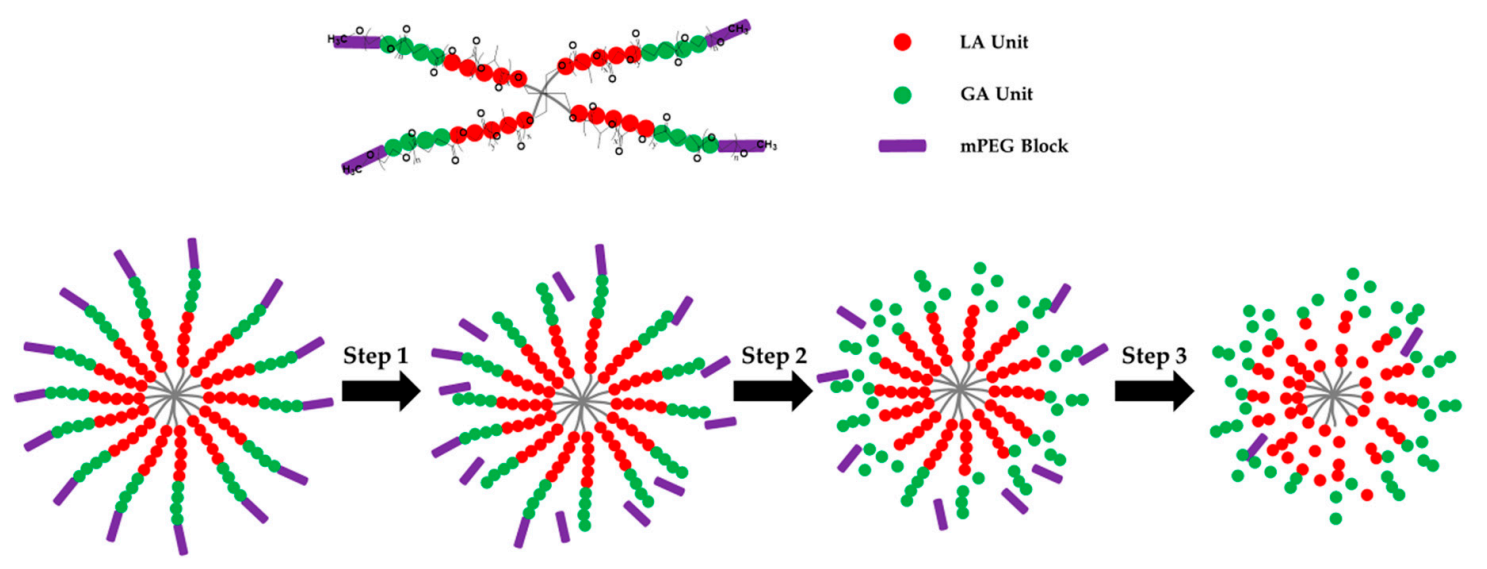

Scheme 2. Degradable mechanism of the prepared 4sPLGA-mPEG block copolymer.

In addition, the in vitro release profiles of indomethacin (IMC), gestodene (GSD), and ethinyl estradiol (EE) were fitted well with the Higuchi model as shown in Table S2. The Higuchi equation was written as Equation (1). Professor Takeru Higuchi published the derivation of an equation to evaluate the quantification of drug release from thin ointment films into the skin, then to learn more about the drug release mechanism $[59,60]$. Although in vitro release profile of drugs was indeed agreed with the Higuchi model, in vivo release profiles still need to be further analyzed. Here, the prepared 4sPLGA-mPEG copolymer was used as a drug release matrix, the transport from this copolymer hydrogel in vaginal site might often lead to release under conditions that were inconsistent with Higuchi's behavior, especially in the vaginal environment, such as that the hydrogel has adhered to mucus layer, so edge effects need to be considered (edge effects are negligible as one of Higuchi conditions) [61]. Furthermore, the anatomy of the vagina and vascular supply makes this organ a special route of drug administration, and the contraceptive drugs are particularly suitable delivering through the vaginal epithelium, which allows quick absorption and unaffected by gastrointestinal disturbance $[18,62]$. It was known that the vaginal epithelium with a large area of high vascularization, was highly permeable to small molecules [63]. The multi-drug released from 4sPLGA-mPEG block copolymer hydrogel by drug diffusion and the biodegradability rate of the copolymer has a significant influence on the drug release profile. In the vaginal environment, some of the drugs were released to the vagina, some were absorbed by vaginal epithelial cells, as shown in Scheme 3. In vivo release profiles of drugs in simulated vagina closer to real vaginal environment need to be explored in the future.

$$
M_{t} / M_{\infty}=k t^{1 / 2}+b
$$

where $M_{t}$ is defined as the amount of drug released at time $t$, and $M_{\infty}$ is the amount of drug released as time approaches infinity.

Next, the 4sPLGA-mPEG copolymer hydrogels loaded with multi-drug with different dosages were injected into the vagina of SD rats to investigate the acute toxicity. For the high dosage group, the morphological changes of uterus, vagina, and intestines, such as hydroncus and adhesion, could be easily estimated by photographic anatomical observation, as shown in Figure 4. At high dosage, the drugs were released from the hydrogel in the vagina, because of a high toxicity on surrounded tissues, some drugs were excluded through the autoimmune responses of SD rats [64]. The histocompatibility and toxicity of multi-drug loaded hydrogel on the whole body need to be further analyzed by organ pathology. Hearts, livers, vagina, uterus, spleen, lungs, and kidneys were collected and sectioned for hematoxylin and eosin staining. The test hydrogels with loading multi-drug at middle and low dosage 
did not show significant damage observed in the organs during the first 3 days (Figure 5, Figure 6, Figure 7, Figure 8, Figures S5-S7).

Lastly, according to in vitro release profiles of multi-drug and histological analysis results, the CP-3 hydrogels loading multi-drug at low dosage content were used for antifertility experiments. The female SD rats without treatment presented $100 \%$ pregnancy rate, and no embryo was observed in the drug-loaded hydrogels group, proved that the prepared hydrogels as a multi-drug carrier was feasible and effective. It was surprising that the SD rats treated with bare hydrogels had a $60 \%$ pregnancy rate. The prepared hydrogels might affect the fertility of female SD rats, the reason was unclear. Some the antimicrobial activity of 4sPLGA-mPEG copolymer hydrogels or influence on sperm viability needs to be further investigated in the future, unfortunately, unfinished in this paper. Some published papers reported that the PEG-based hydrogels (such as PEG-lactic acid hydrogels) showed antimicrobial activity against the primary bacterial vaginosis (BV) pathogen Gardnerella vaginalis [65], and while the copolymers of polylactide and $\varepsilon$-caprolactone were instilled into the vagina of estrous female rabbits, all sperms were dead [66]. The prepared hydrogels might influence the viability of sperms in the vagina, then further reduced the pregnancy rate. In addition, the prepared hydrogels had the potential as microbicides carrier against HIV and HSV, Chlamydia trachomatis and Neisseria gonorrhoeae [67]. The 4sPLGA-mPEG copolymer hydrogels as the multi-contraceptive carrier were easy to administrate for users without the need the surgical procedure. More research on pharmaceutical characterization of multi-drug loaded vaginal hydrogels was needed before clinical applications in order to optimize safety, efficacy, and acceptability.

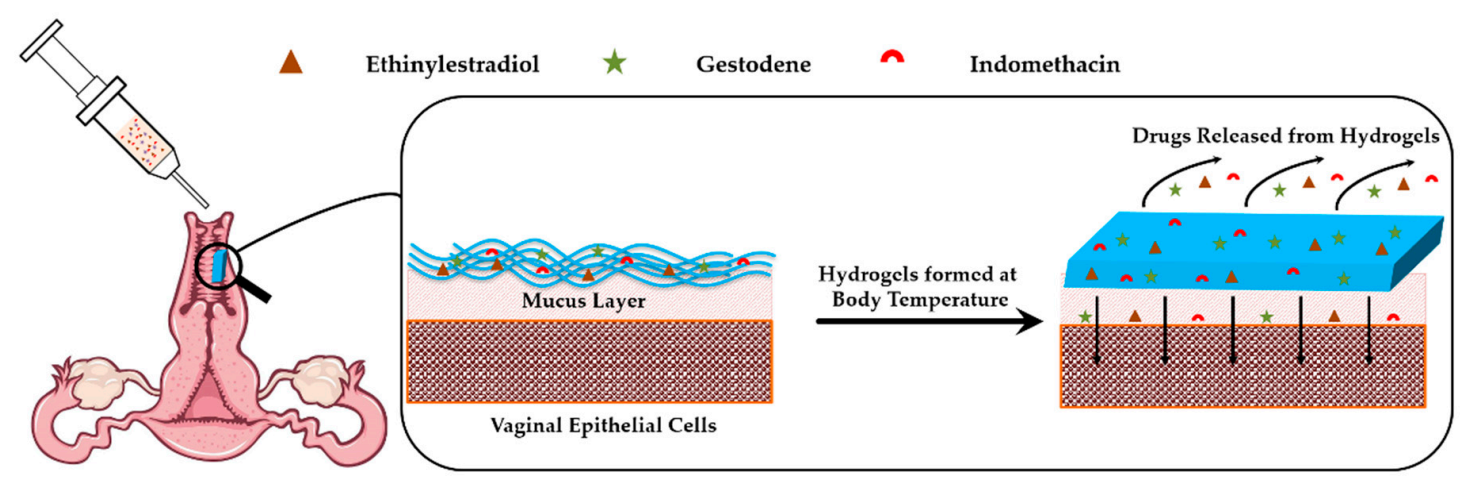

Scheme 3. The prepared 4sPLGA-mPEG block copolymer solution loaded with three drugs could be injected into the vagina, and formed to mucoadhesive vaginal hydrogels at body temperature, then the multi-drugs released from hydrogels, and release profiles could be regulated by adjusting the lactide/glycolide (LA/GA) ratio.

\section{Conclusions}

In summary, we offered a report on temperature-sensitive star-shaped 4sPLGA-mPEG block copolymer hydrogels with loading multi-contraceptive for vaginal application. In vitro controlled release profiles of three contraceptives were investigated via the HPLC method. The HPLC condition was first determined as follows: the maximum absorption peaks of IMC and EE were $\sim 210 \mathrm{~nm}$, and the one of GSD was $\sim 240 \mathrm{~nm}$; volume ratio of optimal mobile phase was 53:47; and the retention time of IMC, GSD, and EE were 11.18, 13.11, and $15.57 \mathrm{~min}$. In vitro release study showed that cumulative release amount of IMC, GSD, and EE in copolymer hydrogels increased with decreasing LA/GA mol ratio from 9 to 1 , suggested that drugs release was not only controlled by drugs diffusion but also mainly by degradability of copolymer hydrogels. In addition, in vitro release profiles of IMC, GSD, and EE were well fitted with the Higuchi model. Lastly, in vivo evaluation of copolymer hydrogels with loading drugs, including acute toxicity and antifertility experiment, was subsequently investigated. For high dosage group, slight hydroncus of the uterus was observed on day 1. Swelling of the uterus became extremely severe and intestinal adhesion was also found at day 3 . Uterus and intestines 
ulcerated at day 5. Regarding the middle dosage group, no festering of tissues was observed and blood coagulum existed in the uterus at a different defined time. For low dosage group, no significant tissue necrosis was observed at the different indicated time. No embryo was observed in the low dosage drug-loaded hydrogel group, indicated that prepared copolymer hydrogel system with packing multi-drug was feasible as a novel contraception method.

Supplementary Materials: The following are available online at http://www.mdpi.com/2076-3417/9/8/1638/s1, Table S1: Preparation of simulated vaginal fluid solution by using different chemicals, Table S2: Fitting parameters of various drug release by using Higuchi kinetic model, Figure S1: GPC traces of prepared CP-1, CP-2, and CP-3 block copolymers, Figure S2: Standard curves of IMC, GSD, and EE for measuring release of drugs, Figure S3: The release amounts of IMC, GSD, and EE from the prepared 4sPLGA-mPEG block copolymer hydrogels, Figure S4: Fitting curve of cumulative release of GSD using Higuchi kinetic model, Figure S5: HE staining of SD rat hearts at day 1,3, and 5 after injecting 4sPLGA-mPEG block copolymer hydrogels with different dosages into vagina, Figure S6: HE staining of SD rat lungs at day 1,3, and 5 after injecting 4sPLGA-mPEG block copolymer hydrogels with different dosages into vagina, Figure S7: HE staining of SD rat kidneys at day 1, 3, and 5 after injecting 4sPLGA-mPEG block copolymer hydrogels with different dosages into vagina, Figure S8: TEM of CP-3 block copolymer solution at different concentrations.

Author Contributions: All authors discussed and agreed on the contents of the manuscript. Conceptualization, L.N., P.Z., and J.S.; methodology, L.N., H.Y., P.Z., and J.S.; formal analysis, L.N., P.Z., J.D., M.S., and J.S.; investigation, L.N., P.Z., P.D., C.J., and J.S.; resources, L.N., P.Z., Y.H., and J.S.; data curation, L.N., P.Z., Q.Z., and J.S.; writing - original draft preparation, L.N., P.Z., and J.S.; writing-review and editing, L.N., J.D., M.S., C.J., H.Y., Y.H., and J.S.; visualization, L.N., Q.Z., and J.S.; supervision, L.N. and J.S.; project administration, L.N. and J.S.; funding acquisition, L.N. and J.S.

Funding: This research was funded by the National Natural Science Foundation of China No. 31700840, and the Key Scientific Research Project of Henan Province (18B430013, 18A150049), Research Fund from Health Commission of Hubei Province (WJ2019M038), and Wuhan Municipal Health and Family Planning Research Fund (WX18C23).

Acknowledgments: This research was supported by the Nanhu Scholars Program for Young Scholars of XYNU. The authors would like to thank the group of Dong Chen from Wuhan Hanyang Hospital for animal experiments and staining pictures analysis. We acknowledge the excellent technical assistance of Xiangchi Peng from Family Planning Research Institute, Tongji Medical College, Huazhong University of Science and Technology. We also acknowledge the manuscript revision of Xiaoyan Wei from the Max Planck Institute for Molecular Genetics, Germany.

Conflicts of Interest: The authors declare no conflict of interest.

\section{References}

1. Cleland, J.; Conde-Agudelo, A.; Peterson, H.; Ross, J.; Tsui, A. Contraception and health. Lancet 2012, 380, 149-156. [CrossRef]

2. Peipert, J.F.; Madden, T.; Allsworth, J.E.; Secura, G.M. Preventing unintended pregnancies by providing No-Cost contraception. Obstet. Gynecol. 2012, 120, 1291-1297. [CrossRef] [PubMed]

3. Peterson, H.B. Sterilization. Obstet. Gynecol. 2008, 111, 189-203. [CrossRef]

4. Farley, T.M.M.; Rowe, P.J.; Meirik, O.; Rosenberg, M.J.; Chen, J.-H. Intrauterine devices and pelvic inflammatory disease: An international perspective. Lancet 1992, 339, 785-788. [CrossRef]

5. Beining, R.M.; Dennis, L.K.; Smith, E.M.; Dokras, A. Meta-analysis of intrauterine device use and risk of endometrial cancer. Ann. Epidemiol. 2008, 18, 492-499. [CrossRef]

6. Castellsagué, X.; Díaz, M.; Vaccarella, S.; de Sanjosé, S.; Muñoz, N.; Herrero, R.; Franceschi, S.; Meijer, C.J.L.M.; Bosch, F.X. Intrauterine device use, cervical infection with human papillomavirus, and risk of cervical cancer: A pooled analysis of 26 epidemiological studies. Lancet Oncol. 2011, 12, 1023-1031. [CrossRef]

7. Cheng, L.; Gülmezoglu, A.M.; Piaggio, G.G.; Ezcurra, E.E.; Look, P.P.V. Interventions for emergency contraception. Cochrane Database Syst. Rev. 2008. [CrossRef]

8. International Collaboration of Epidemiological Studies of Cervical Cancer. Cervical cancer and hormonal contraceptives: Collaborative reanalysis of individual data for 16573 women with cervical cancer and 35509 women without cervical cancer from 24 epidemiological studies. Lancet 2007, 370, 1609-1621. [CrossRef]

9. Lidegaard, Ø.; Løkkegaard, E.; Svendsen, A.L.; Agger, C. Hormonal contraception and risk of venous thromboembolism: National follow-up study. BMJ 2009, 339, b2890. [CrossRef] 
10. Curtis, K.M.; Nanda, K.; Kapp, N. Safety of hormonal and intrauterine methods of contraception for women with HIV/AIDS: A systematic review. AIDS 2009, 23, S55. [CrossRef]

11. Srikrishna, S.; Cardozo, L. The vagina as a route for drug delivery: A review. Int. Urogynecol. J. 2013, 24, 537-543. [CrossRef] [PubMed]

12. Furst, T.; Piette, M.; Lechanteur, A.; Evrard, B.; Piel, G. Mucoadhesive cellulosic derivative sponges as drug delivery system for vaginal application. Eur. J. Pharm. Biopharm. 2015, 95, 128-135. [CrossRef]

13. Ensign, L.M.; Cone, R.; Hanes, J. Nanoparticle-based drug delivery to the vagina: A review. J. Control. Release 2014, 190, 500-514. [CrossRef]

14. Jensen, J.T. Vaginal ring delivery of selective progesterone receptor modulators for contraception. Contraception 2013, 87, 314-318. [CrossRef]

15. Han, Y.A.; Singh, M.; Saxena, B.B. Development of vaginal rings for sustained release of nonhormonal contraceptives and anti-HIV agents. Contraception 2007, 76, 132-138. [CrossRef]

16. Machado, R.M.; Palmeira-De-Oliveira, A.; Martinez-De-Oliveira, J.; Palmeira-De-Oliveira, R. Vaginal films for drug delivery. J. Pharm. Sci.-US 2013, 102, 2069-2081. [CrossRef] [PubMed]

17. Loxley, A.; Mitchnick, M.; Okoh, O.; McConnell, J.; Goldman, L.; Morgan, C.; Clark, M.; Friend, D.R. Ethylene vinyl acetate intravaginal rings for the simultaneous delivery of the antiretroviral UC781 and contraceptive levonorgestrel. Drug Deliv. Transl. Res. 2011, 1, 247-255. [CrossRef]

18. Sitruk-Ware, R.; Nath, A.; Mishell, D.R. Contraception technology: Past, present and future. Contraception 2013, 87, 319-330. [CrossRef] [PubMed]

19. Das Neves, J.; Amiji, M.; Sarmento, B. Mucoadhesive nanosystems for vaginal microbicide development: Friend or foe? Wires Nanomed. Nanobiotechnol. 2011, 3, 389-399. [CrossRef]

20. Sigurdsson, H.H.; Kirch, J.; Lehr, C.-M. Mucus as a barrier to lipophilic drugs. Int. J. Pharm. 2013, 453, 56-64. [CrossRef]

21. Li, J.; Mooney, D.J. Designing hydrogels for controlled drug delivery. Nat. Rev. Mater. 2016, 1, 16071. [CrossRef] [PubMed]

22. das Neves, J.; Bahia, M.F. Gels as vaginal drug delivery systems. Int. J. Pharm. 2006, 318, 1-14. [CrossRef]

23. Wolinsky, J.B.; Colson, Y.L.; Grinstaff, M.W. Local drug delivery strategies for cancer treatment: Gels, nanoparticles, polymeric films, rods, and wafers. J. Control. Release 2012, 159, 14-26. [CrossRef] [PubMed]

24. Das Neves, J.; Nunes, R.; Machado, A.; Sarmento, B. Polymer-based nanocarriers for vaginal drug delivery. Adv. Drug Deliver. Rev. 2015, 92, 53-70. [CrossRef] [PubMed]

25. Jalalvandi, E.; Shavandi, A. In situ-forming and $\mathrm{pH}$-responsive hydrogel based on chitosan for vaginal delivery of therapeutic agents. J. Mater. Sci. Mater. Med. 2018, 29, 158. [CrossRef]

26. Singh, V.K.; Sagiri, S.S.; Pal, K.; Khade, S.M.; Pradhan, D.K.; Bhattacharya, M.K. Gelatin-carbohydrate phase-separated hydrogels as bioactive carriers in vaginal delivery: Preparation and physical characterizations. J. Appl. Polym. Sci. 2014, 131. [CrossRef]

27. Koetting, M.C.; Peters, J.T.; Steichen, S.D.; Peppas, N.A. Stimulus-responsive hydrogels: Theory, modern advances, and applications. Mater. Sci. Eng. R Rep. 2015, 93, 1-49. [CrossRef]

28. Yang, J.-A.; Yeom, J.; Hwang, B.W.; Hoffman, A.S.; Hahn, S.K. In situ-forming injectable hydrogels for regenerative medicine. Prog. Polym. Sci. 2014, 39, 1973-1986. [CrossRef]

29. Almomen, A.; Cho, S.; Yang, C.-H.; Li, Z.; Jarboe, E.A.; Peterson, C.M.; Huh, K.M.; Janát-Amsbury, M.M. Thermosensitive progesterone hydrogel: A safe and effective new formulation for vaginal application. Pharm. Res. 2015, 32, 2266-2279. [CrossRef]

30. Taurin, S.; Almomen, A.A.; Pollak, T.; Kim, S.J.; Maxwell, J.; Peterson, C.M.; Owen, S.C.; Janát-Amsbury, M.M. Thermosensitive hydrogels a versatile concept adapted to vaginal drug delivery. J. Drug Target. 2018, 26, 533-550. [CrossRef]

31. Jeong, B.; Kim, S.W.; Bae, Y.H. Thermosensitive sol-gel reversible hydrogels. Adv. Drug Deliv. Rev. 2012, 64, 154-162. [CrossRef]

32. Gupta, K.M.; Barnes, S.R.; Tangaro, R.A.; Roberts, M.C.; Owen, D.H.; Katz, D.F.; Kiser, P.F. Temperature and $\mathrm{pH}$ sensitive hydrogels: An approach towards smart semen-triggered vaginal microbicidal vehicles. J. Pharm. Sci.-US 2007, 96, 670-681. [CrossRef]

33. Patel, N.; Thakkar, V.; Moradiya, P.; Gandhi, T.; Gohel, M. Optimization of curcumin loaded vaginal in-situ hydrogel by box-behnken statistical design for contraception. J. Drug Deliv. Sci. Technol. 2015, 29, 55-69. [CrossRef] 
34. Aka-Any-Grah, A.; Bouchemal, K.; Koffi, A.; Agnely, F.; Zhang, M.; Djabourov, M.; Ponchel, G. Formulation of mucoadhesive vaginal hydrogels insensitive to dilution with vaginal fluids. Eur. J. Pharm. Biopharm. 2010, 76, 296-303. [CrossRef]

35. Bouchemal, K.; Frelichowska, J.; Martin, L.; Lievin-Le Moal, V.; Le Grand, R.; Dereuddre-Bosquet, N.; Djabourov, M.; Aka-Any-Grah, A.; Koffi, A.; Ponchel, G. Note on the formulation of thermosensitive and mucoadhesive vaginal hydrogels containing the miniCD4 M48U1 as anti-HIV-1 microbicide. Int. J. Pharm. 2013, 454, 649-652. [CrossRef] [PubMed]

36. Liu, Y.; Yang, F.; Feng, L.; Yang, L.; Chen, L.; Wei, G.; Lu, W. In vivo retention of poloxamer-based in situ hydrogels for vaginal application in mouse and rat models. Acta Pharm. Sin. B 2017, 7, 502-509. [CrossRef]

37. Ravani, L.; Esposito, E.; Bories, C.; Moal, V.L.-L.; Loiseau, P.M.; Djabourov, M.; Cortesi, R.; Bouchemal, K. Clotrimazole-loaded nanostructured lipid carrier hydrogels: Thermal analysis and in vitro studies. Int. J. Pharm. 2013, 454, 695-702. [CrossRef] [PubMed]

38. Chen, X.; Li, F.; Feng, L.; Yu, L.; Ding, J. An Injectable Thermogel containing levonorgestrel for long-acting contraception and fertility control of animals. J. Biomed. Nanotechnol. 2017, 13, 1357-1468. [CrossRef]

39. Janagam, D.R.; Wang, L.; Ananthula, S.; Johnson, J.R.; Lowe, T.L. An accelerated release study to evaluate long-acting contraceptive levonorgestrel-containing in situ forming depot systems. Pharmaceutics 2016, 8, 28. [CrossRef]

40. Zou, P.; Suo, J.; Nie, L.; Feng, S. Temperature-sensitive biodegradable mixed star-shaped block copolymers hydrogels for an injection application. Polymer 2012, 53, 1245-1257. [CrossRef]

41. Chen, D.; Zhang, C.; Huo, H.; Ji, C.; Sun, M.; Nie, L. Injectable temperature-sensitive hydrogel with VEGF loaded microspheres for vascularization and bone regeneration of femoral head necrosis. Mater. Lett. 2018, 229, 138-141. [CrossRef]

42. Nie, L.; Chang, P.; Sun, M.; Huo, H.; Zhang, C.; Ji, C.; Wei, X.; Zhou, Q.; Guo, P.; Yuan, H. Composite hydrogels with the simultaneous release of VEGF and MCP-1 for enhancing angiogenesis for bone tissue engineering applications. Appl. Sci. 2018, 8, 2438. [CrossRef]

43. Merz, M.; Kroll, R.; Lynen, R.; Bangerter, K. Bleeding pattern and cycle control of a low-dose transdermal contraceptive patch compared with a combined oral contraceptive: A randomized study. Contraception 2015, 91, 113-120. [CrossRef]

44. Nie, L.; Zou, P.; Feng, S.; Suo, J. Temperature-sensitive star-shaped block copolymers hydrogels for an injection application: Phase transition behavior and biocompatibility. J. Mater. Sci. Mater. Med. 2013, 24, 689-700. [CrossRef] [PubMed]

45. Borges, S.; Silva, J.; Teixeira, P. Survival and biofilm formation by Group B streptococci in simulated vaginal fluid at different pHs. Antonie Leeuwenhoek 2012, 101, 677-682. [CrossRef]

46. Zou, P.; Suo, J.; Nie, L.; Feng, S. Temperature-responsive biodegradable star-shaped block copolymers for vaginal gels. J. Mater. Chem. 2012, 22, 6316-6326. [CrossRef]

47. Lee, K.-P.; Lee, J.-H.; Kim, T.-S.; Kim, T.-H.; Park, H.-D.; Byun, J.-S.; Kim, M.-C.; Jeong, W.-I.; Calvisi, D.F.; Kim, J.-M.; et al. The Hippo-Salvador pathway restrains hepatic oval cell proliferation, liver size, and liver tumorigenesis. Proc. Natl. Acad. Sci. USA 2010, 107, 8248-8253. [CrossRef]

48. Millas, I.; Liquidato, B.M.; de Sousa Buck, H.; Barros, M.D.; Paes, R.A.P.; Dolci, J.E.L. Evaluation of estrogenic receptors in the nasal mucosa of women taking oral contraceptives. Contraception 2011, 83, 571-577. [CrossRef] [PubMed]

49. Bahamondes, M.V.; Castro, S.; Marchi, N.M.; Marcovici, M.; Andrade, L.A.L.A.; Fernandes, A.; Bahamondes, L. Human vaginal histology in long-term users of the injectable contraceptive depot-medroxyprogesterone acetate. Contraception 2014, 90, 117-122. [CrossRef] [PubMed]

50. Seon, C.S.; Park, Y.S.; Park, S.H.; Ryu, S.R.; Jo, Y.J.; Kim, S.H.; Son, B.K.; Ahn, S.B. A Case of Oral-contraceptive Related Ischemic Colitis in Young Woman. Clin. Endosc. 2011, 44, 129-132. [CrossRef] [PubMed]

51. Crist, E.; Mora, C.; Engelman, R. The interaction of human population, food production, and biodiversity protection. Science 2017, 356, 260-264. [CrossRef] [PubMed]

52. Subramanian, B.; Rameshbabu, A.P.; Ghosh, K.; Jha, P.K.; Jha, R.; Murugesan, S.; Chattopadhyay, S.; Dhara, S.; Mondal, K.C.; Basak, P.; et al. Impact of styrene maleic anhydride (SMA) based hydrogel on rat fallopian tube as contraceptive implant with selective antimicrobial property. Mater. Sci. Eng. C 2019, 94, 94-107. [CrossRef] [PubMed] 
53. Turok, D.K.; Gawron, L.M.; Lawson, S. New developments in long-acting reversible contraception: The promise of intrauterine devices and implants to improve family planning services. Fertil. Steril. 2016, 106, 1273-1281. [CrossRef] [PubMed]

54. Vanić, Ž.; Škalko-Basnet, N. Nanopharmaceuticals for improved topical vaginal therapy: Can they deliver? Eur. J. Pharm. Biopharm. 2013, 50, 29-41. [CrossRef]

55. Mahinroosta, M.; Jomeh Farsangi, Z.; Allahverdi, A.; Shakoori, Z. Hydrogels as intelligent materials: A brief review of synthesis, properties and applications. Mater. Today Chem. 2018, 8, 42-55. [CrossRef]

56. Hasan Turabee, M.; Thambi, T.; Trang Duong, H.T.; Hoon Jeong, J.; Sung Lee, D. A pH- and temperature-responsive bioresorbable injectable hydrogel based on polypeptide block copolymers for the sustained delivery of proteins in vivo. Biomater. Sci.-UK 2018, 6, 661-671. [CrossRef]

57. Zhang, W.; Jin, X.; Li, H.; Zhang, R.; Wu, C. Injectable and body temperature sensitive hydrogels based on chitosan and hyaluronic acid for $\mathrm{pH}$ sensitive drug release. Carbohydr. Polym. 2018, 186, 82-90. [CrossRef]

58. Zou, P.; Nie, L.; Feng, S.; Suo, J. Synthesis, micellization and gelation of temperature-responsive star-shaped block copolymers. Polym. Adv. Technol. 2013, 24, 460-465. [CrossRef]

59. Higuchi, T. Rate of release of medicaments from ointment bases containing drugs in suspension. J. Pharm. Sci. 1961, 50, 874-875. [CrossRef]

60. Paul, D.R. Elaborations on the Higuchi model for drug delivery. Int. J. Pharm. 2011, 418, 13-17. [CrossRef] [PubMed]

61. Siepmann, J.; Peppas, N.A. Higuchi equation: Derivation, applications, use and misuse. Int. J. Pharm. 2011, 418, 6-12. [CrossRef] [PubMed]

62. Sitruk-Ware, R. Vaginal delivery of contraceptives. Expert Opin. Drug Deliv. 2005, 2, 729-736. [CrossRef] [PubMed]

63. Ensign, L.M.; Tang, B.C.; Wang, Y.-Y.; Tse, T.A.; Hoen, T.; Cone, R.; Hanes, J. Mucus-penetrating nanoparticles for vaginal drug delivery protect against herpes simplex virus. Sci. Transl. Med. 2012, 4, 138ra79. [CrossRef]

64. Maes, M.; Kubera, M.; Leunis, J.-C.; Berk, M.; Geffard, M.; Bosmans, E. In depression, bacterial translocation may drive inflammatory responses, oxidative and nitrosative stress (O\&NS), and autoimmune responses directed against O\&NS-damaged neoepitopes. Acta Psychiatr. Scand. 2013, 127, 344-354. [CrossRef] [PubMed]

65. Sundara Rajan, S.; Turovskiy, Y.; Singh, Y.; Chikindas, M.L.; Sinko, P.J. Poly(ethylene glycol) (PEG)-lactic acid nanocarrier-based degradable hydrogels for restoring the vaginal microenvironment. J. Control. Release 2014, 194, 301-309. [CrossRef] [PubMed]

66. Saxena, B.B.; Singh, M.; Gospin, R.M.; Chu, C.C.; Ledger, W.J. Efficacy of nonhormonal vaginal contraceptives from a hydrogel delivery system. Contraception 2004, 70, 213-219. [CrossRef]

67. Neyts, J.; Kristmundsdóttir, T.; Clercq, E.D.; Thormar, H. Hydrogels containing monocaprin prevent intravaginal and intracutaneous infections with HSV-2 in mice: Impact on the search for vaginal microbicides. J. Med. Virol. 2000, 61, 107-110. [CrossRef]

(C) 2019 by the authors. Licensee MDPI, Basel, Switzerland. This article is an open access article distributed under the terms and conditions of the Creative Commons Attribution (CC BY) license (http://creativecommons.org/licenses/by/4.0/). 